\title{
Research Paper \\ Interpersonal Mindfulness in Parenting, Parental Competence, and Perceived Social Support in the Mothers of Children with Special Needs
}

\author{
Seyyedeh Fatemeh Mousavi* ${ }^{* 1}$, Solmaz Dabiri ${ }^{2}$ \\ 1.Associate Professor, Department of Psychology, Women Research Center, Alzahra University, Tehran, Iran \\ 2. Assistant Professor, Department of Psychology, North Tehran Branch, Islamic Azad University, Tehran, Iran
}

Citation: Mousavi SF, Dabiri S. Interpersonal mindfulness in parenting, parental competence, and perceived social support in the mothers of children with special needs. J Child Ment Health. 2021; 7(4): 95-111.
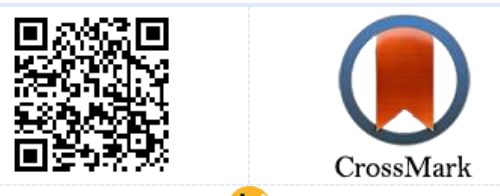

URL: http://childmentalhealth.ir/article-1-813-en.html

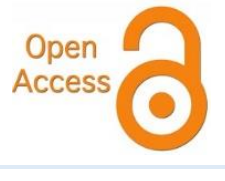

$\underline{20.1001 .1 .24233552 .1399 .7 .4 .6 .4}$

\section{A R T I C L E I N F O}

\section{Keywords:}

Interpersonal mindfulness in parenting, parental competence, social support, children with special needs

Received: 4 May 2019 Accepted: 18 Sep 2019 Available: 19 Mar 2021

\begin{abstract}
A B S T R A C T
Background and Purpose: The birth of a child is an exciting but stressful event for the parents. Meanwhile, the birth of a child with special needs imposes more stress on the parents and requires special physical and mental strength to parenting the child. The current study was conducted to compare the interpersonal mindfulness in parenting, parental competence, and perceived social support in the mothers of children with or without special needs.

Method: This study was a descriptive research with comparative analytical design. The statistical population included two groups of mothers of children with or without special needs living in Qazvin in 2018. Among them, 160 mothers (87 having a child without special needs and 73 having a child with special needs) were selected voluntarily by convenience sampling to participate in the study. The research tools included Interpersonal Mindfulness in Parenting Scale (Duncan, 2007), Parenting Sense of Competence Scale (Johnston and Mash, 1989) and Multidimensional Scale of Perceived Social Support (Zimet, Dahlem, Zimet, and Farley, 1988).

Results: The results showed that there was a significant difference between the two groups of mothers of children with or without special needs in terms of interpersonal mindfulness in parenting $(\mathrm{p}<.01)$ and parental competence $(\mathrm{p}<.05)$; however no significant difference was found in terms of perceived social support ( $\mathrm{p}>$.4).

Conclusion: Results showed lower scores of parental competence and higher scores of interpersonal mindfulness in parenting in the mothers of children with special needs compared to the mothers of children without special needs. The implications of the result are discussed in the article.
\end{abstract}

* Corresponding author: Seyyedeh Fatemeh Mousavi, Associate Professor, Department of Psychology, Women Research Center, Alzahra University, Tehran, Iran.

E-mail: F.mousavi@alzahra.ac.ir

Tel: (+98) 2185692084

2476-5740/ (C) 2021 The Authors. This is an open access article under the CC BY-NC-ND license

(https://creativecommons.org/licenses/by-nc-nd/4.0/). 


\section{Extended Abstract}

\section{Introduction}

The birth of a child is an exciting but stressful event for the parents (1). However, the birth of a child with special needs turns the parents' expectation into frustration, imposes excessive stress on them, and disturbs their adaptive behaviors in life for a long time $(3,4,5,6)$. Upbringing a child with special needs requires special physical and mental strength to deal with and manage the child's behaviors.

The mindfulness-based parenting approach focuses on present moment awareness, present-centered attention, and non-judgmental acceptance (of the self and the child) in parent-child interactions (20) that affect the competence of mothers to satisfy their children's needs (21). Mothers who are feeling more efficient are more aware of their child's emotions at the moment and report lower levels of behavioral problems in their children (7). Mothers of children with special needs acquire part of the sense of efficacy through the social support of the family and friends. Although, limited evidence suggests that the effect of perceived support on the stress of these parents is not persistently significant $(34,35)$, most research indicate that such a support increases the capacity of coping with difficult life situations, facilitates accepting the flow of life, and increases the maternal compassionate attitude towards the needs of the children with special needs (26).

Findings also show that maladaptive parental interaction patterns can result from automatic parental behaviors (10) that affect parental wellbeing $(12,13)$, parental stress $(14)$, quality of parentchild relationship $(16,17,18)$, and the psychological adjustment of parent-child interactions (19). Because of the challenges embedded in the parent-child interactions experienced by the parents of children with special needs, more research should be done about present-centered attention to the needs of these children as a new approach to the parental interactions, sense of competence, and perception of environmental supports. So, the current study was carried out to compare the interpersonal mindfulness in parenting, parental competence, and perceived social support in the mothers of children with or without special needs in Qazvin city.

\section{Method}

This study was a descriptive research with comparative analytical design. The population included two groups of mothers of children with or without special needs living in Qazvin in 2018. The study sample selected by convenience and volunteer sampling included 87 mothers of children without special needs with the mean and standard deviation of $36.71 \pm 6.33$ and the age range of 24-55, selected from public centers of the city, and 73 mothers of children with special needs (physical-motor disability and hearing impairment) with the mean and standard deviation of $33.6 \pm 6.21$ and the age range of 22-49 who had referred to three rehabilitation centers for the disabled under the supervision of Social Welfare Administration of Qazvin province. The research tools included Interpersonal Mindfulness in Parenting Scale (Duncan, 2007) (39), including three components of present-centered awareness and attention, nonjudgmental acceptance of children's thoughts and feelings, and non-reactivity towards adopted cultural norms of children's behaviors; Parenting Sense of Competence Scale (Johnston and Mash, 1989) (42); and the Multidimensional Scale of Perceived Social Support (Zimet, Dahlem, Zimet, and Farley, 1988) (44).

\section{Results}

The results of Table 1 show the mean, standard deviation and ANOVA of the studied variables in two groups of mothers of children with or without special needs.

The Wilks' Lambda showed that the effect of having a child with special needs on the linear combination of interpersonal mindfulness in parenting and parental competence was significant $\left(\mathrm{F}=2.05, \mathrm{p}<.02, \eta^{2}=.087\right)$. Results of ANOVA indicated that there was a significant difference between the groups in terms of interpersonal mindfulness in parenting and nonjudgmental acceptance of children $(\mathrm{F}(158,1)=8.25, \mathrm{p}<.005$, $\left.\eta^{2}=0.05\right)$ and parental competence $(\mathrm{F}(158,1)=3.66$, $\left.\mathrm{p}<.05, \eta^{2}=0.02\right)$. This implies that mothers of children with special needs had higher scores in interpersonal mindfulness in parenting and lower 
scores in parental competence compared to mothers of children without special needs. Groups were not significantly different in perceived social support $(\mathrm{F}$ $\left.(158,1)=2.69, p>.1, \eta^{2}=0.017\right)$. (Table 1)

Table 1. Mean, SD and ANOVA of the studied variables in two groups of mothers

\begin{tabular}{|c|c|c|c|c|}
\hline \multirow{2}{*}{ variables } & $\begin{array}{c}\text { Mothers of children without } \\
\text { special needs }\end{array}$ & $\begin{array}{c}\text { Mothers of children with } \\
\text { special needs }\end{array}$ & Total & \multirow{2}{*}{$\mathbf{F}(p)$} \\
\hline & $\begin{array}{l}(\mathrm{N}=87) \\
M(S D)\end{array}$ & $\begin{array}{l}(\mathrm{N}=73) \\
M(S D)\end{array}$ & $\begin{array}{l}(\mathrm{N}=160) \\
M(S D)\end{array}$ & \\
\hline present-centered attention & $12.5(2.7)$ & $13.13(2.74)$ & $12.78(2.73)$ & $2.15(.14)$ \\
\hline non-judgment & $9.69(2.54)$ & $10.72(2)$ & $10.16(2.3)$ & $8.25(.005)$ \\
\hline non-reactivity & $9.44(1.95)$ & $10.06(2.39)$ & $9.72(2.17)$ & $3.36(.07)$ \\
\hline parenting competence & $37.34(8.72)$ & $34.66(8.19)$ & $36.1(8.56)$ & $3.66(.05)$ \\
\hline family support & $20.92(6.21)$ & $20.35(5.58)$ & $20.66(5.92)$ & $0.35(.6)$ \\
\hline friends' support & $17.12(5.96)$ & $15.54(6.18)$ & $16.4(6.09)$ & $2.69(.1)$ \\
\hline significant-other support & $19.56(6.47)$ & $19.66(5.38)$ & $19.6(5.98)$ & $0.01(.91)$ \\
\hline
\end{tabular}

\section{Conclusion}

This study showed that mothers of children with special needs had more mindfulness than mothers of children without special needs. Different studies suggest that mindfulness in the parents of children with disability is associated with parental well-being $(12,13)$, positive parenting practices and improved parent-child relationship $(16,17,18)$, as well as adjustment in parent-child interactions (19). Physical, cognitive, and emotional deficiencies in the children with special needs may cause persistent concerns for their mothers and may lead the actions and feelings of the mothers towards mindful attention to the needs of these children.

The results of this study also showed that despite reporting low social and emotional supports from friends, mothers of children with special needs were not significantly different from the mothers of children without special needs in terms of perceived social support. This finding is consistent with the results of some studies $(34,35)$; however other studies have shown that the extent of perceived emotional support in parents of children with special needs can be effective in reducing the symptoms of depression, anxiety, and stress in them (30). Having a satisfactory perception of emotional support from others plays an important role in managing and fulfilling maternal responsibilities. As far as the caregiving to these children is concerned, the perceived emotional support and not feeling lonely in coping with the crisis, by making it easy to concentrate on the present time and giving particular attention to the needs of the child, can reduce the concerns of mothers and play an important role in the efficiency of mothers to fulfill the caring responsibilities. The mothers' purposeful awareness and their non-judgmental attention to the disabled child's needs besides the emotional support provided for these mothers can lead to using the multi-care capacity, stimulate conscious and flexible parental behaviors, and increase the sense of competence in them. Anyway this study was performed only on two groups of children with disabilities, so it is recommended to conduct more extensive studies on other groups with disabilities in future studies. 


\section{Quarterly Journal of}

\section{Child Mental Health}

Vol. 7, No. 4, Winter 2021

\section{Ethical Considerations}

Compliance with ethical guidelines

This study was conducted by the ethical codes of human research such as the confidentiality of personal information of participants, obtaining informed consent from center managers and the mothers of both groups to participate in the study, and authority to leave the study at any time of completing the questionnaire in line with the 1960 Helsinki Declaration.

Funding: The present study is the result of the corresponding author's research program entitled "Positive Family-Based Psychology: Focusing on Personal and Systemic Consequences in Iranian Families" that has been done under the financial support of Vice Chancellor for Research and Technology, Alzahra University, with the contract number D97/3/200 dated 16 Apr. 2018 and permission No. 12231 date 16 July 2018 by Welfare Department of Qazvin Province.
Authors' contribution: The corresponding author was responsible for making the coordinations, administrating the questionnaires, analyzing the data, and drafting the article and the second author was responsible for advising on methodology and statistical analysis.

Conflict of interest: This study does not directly or indirectly conflict with the financial or professional interests of any individual or organization.

Acknowledgments: Managers and staff of Rehabilitation Deputy of the Welfare Department of Qazvin Province, the heads of the rehabilitation centers of Shafa, Sina and Parnian, as well as the mothers in both groups participating in the research are appreciated for their cooperation in facilating the implementation of the current study. 


\title{
ذهن آكاهى بينفردى در والدكرى، شايستكى والدينى، و حمايت اجتماعى ادراكى شده مادران داراى كودكى با نيازهاى ويزه
}

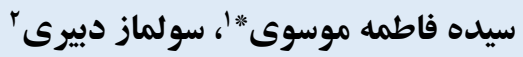

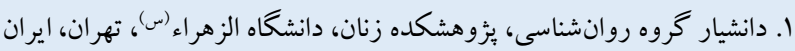

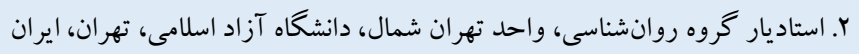

مقاله يخوهشى

جكيده

زمينه و هدف: تولد فرزند رويدادى مهيج و در عين حال يرتنش براى والدين به شمار مىرود. در اين ميان، تولد فرزندى داراى نيازهاى

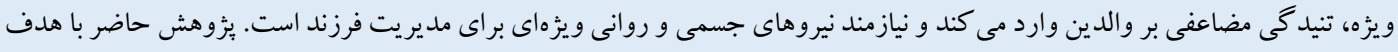

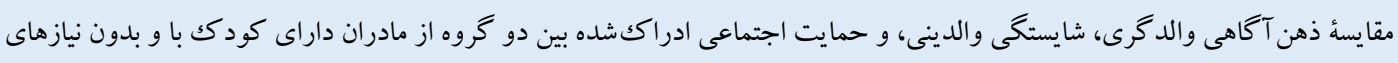
ويثه انجام شد.

روش: روش يُزوهش، توصيفى و از نوع تحليلى مقايسهاى است. جامعهُ آمارى يُوهش دو گروه از مادران كود كان با و بدون نيازهاى ويزٔه

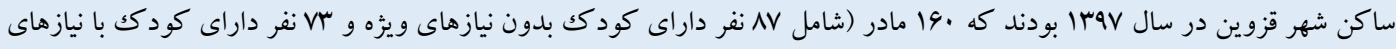

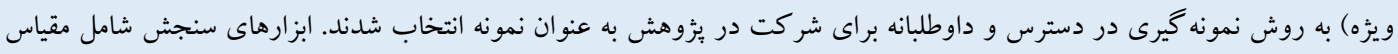

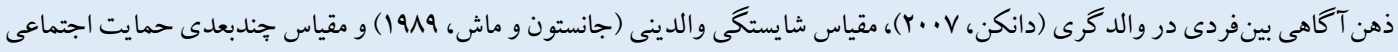
ادراككشده (زيمت، داهلم، زيمت و فارلى، 19191) بود.

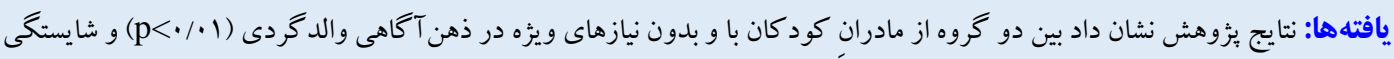

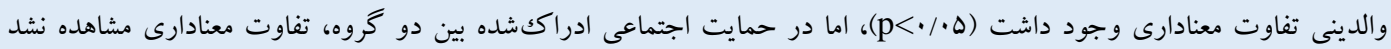

$\cdot(\mathrm{p}>\cdot / \mathrm{f})$

نتيجه كيرى: نتايج حاكى از بايين بودن نمرات شايستخى والدينى و بالا بودن نمرات ذهن آكاهى والدگرى در مادران داراى كود كان با

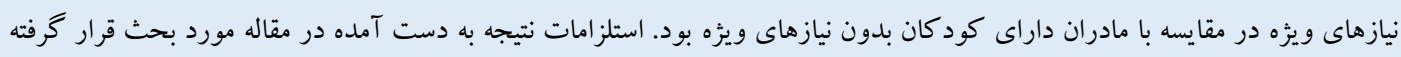

مشخصات مقاله

كليدوازهها:

ذهن آكاهى والدينى، شايستكى،

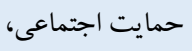
كودكك داراى نيازهاى ويثز
دريافت شده:

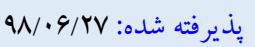
منتشر شده: M9/IY/Y9

* نويسنده مسئول: سيده فاطمه موسوى، دانشيار گروه روانشناسى، ئزوهشكه زنان، دانشگاه الزهراء(س)، تهران، ايران.

رايانامه: F.mousavi@alzahra.ac.ir 
والدگرى مبتنى بر ذهن آكاهى به كاربرد ذهن آكاهى در زمينهُ شـيوه

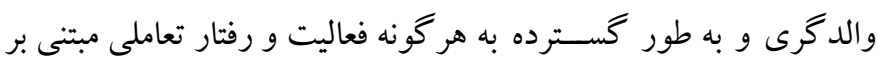

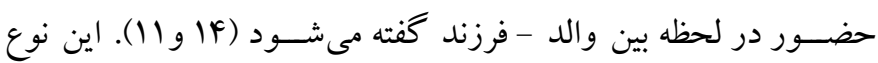

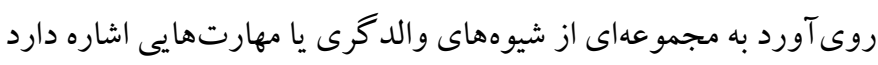

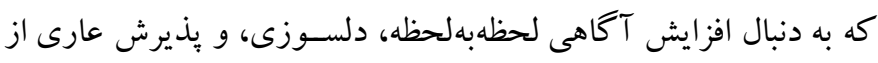

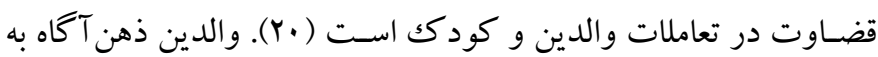

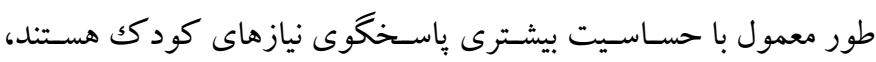

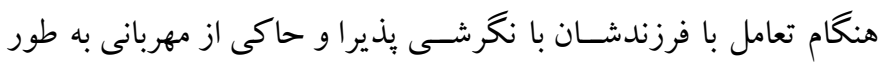

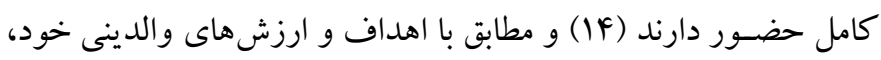
احساسات و رفتار خود را براى برقرارى ارتباط با كودك تنظيم مى كنند

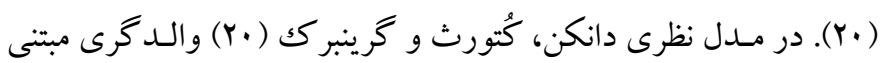

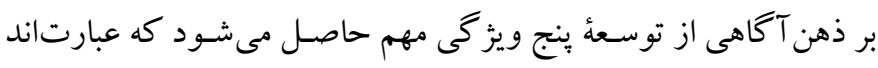

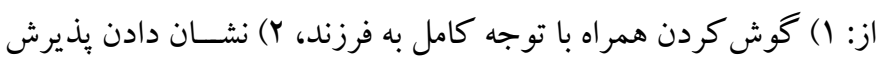

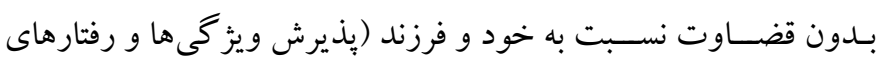

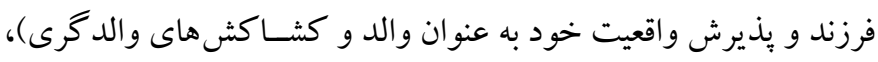

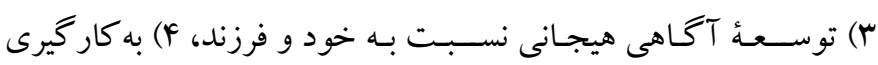

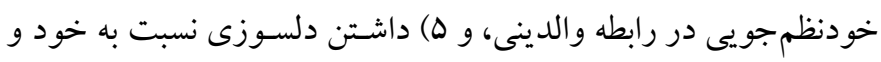

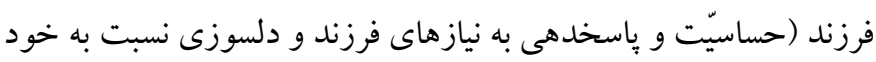

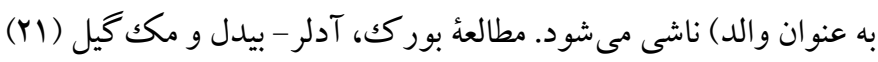

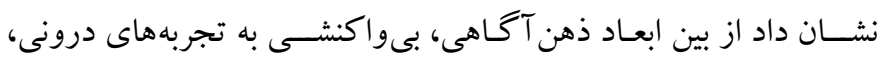
ييشبينى كنندة احسـاس كار آمدى و شايستخى به ويزٔه در مادران است.

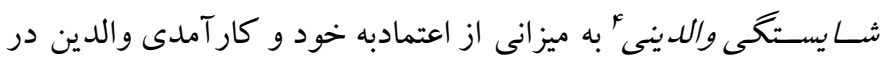

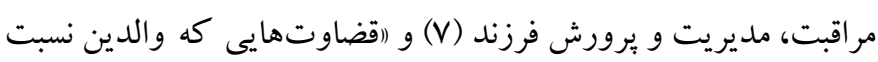

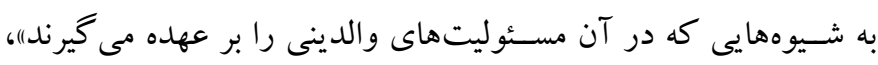

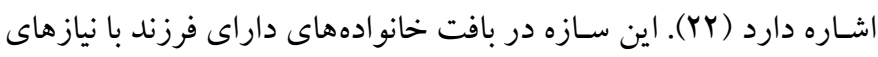

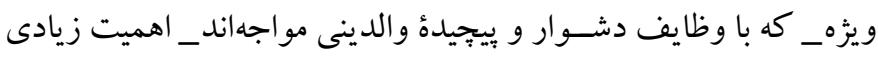

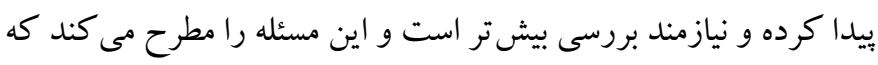

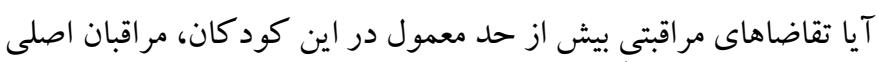

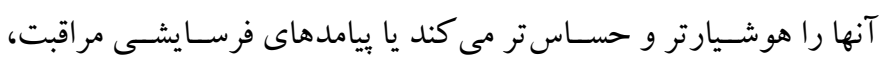

مقلدمه

براى بيشتر خانو ادهها، والدگرى 'منبع مســمر شــادى، لذت همراه با

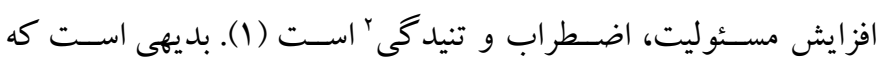

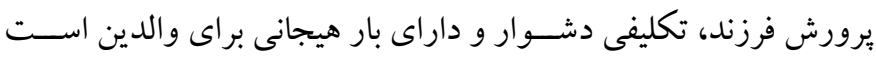

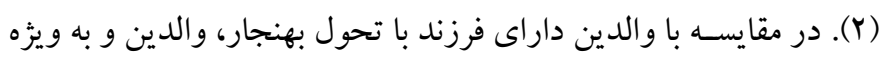

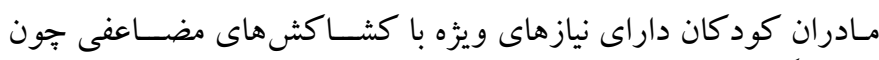

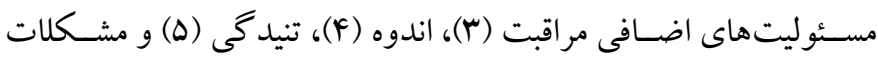

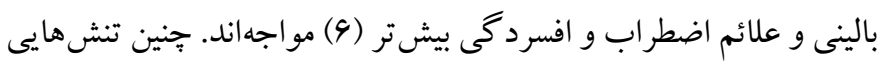

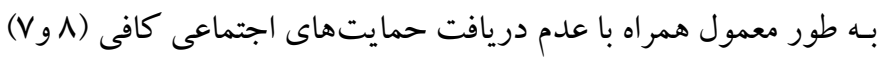

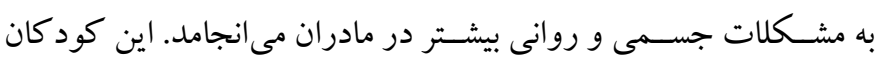

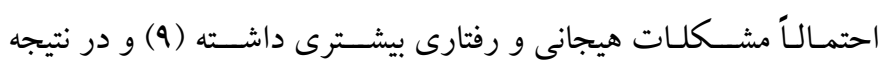

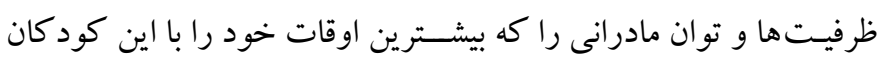

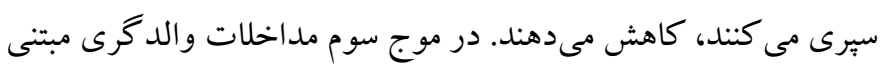

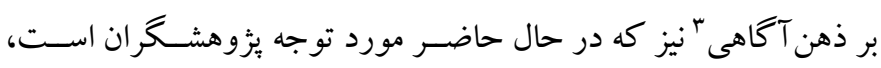

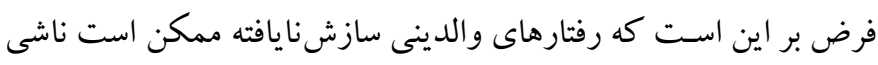

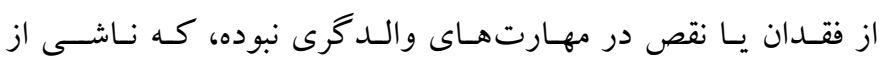

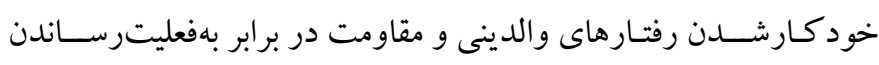

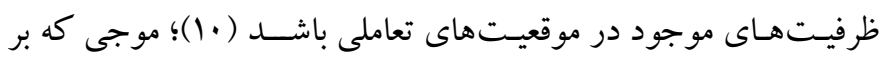

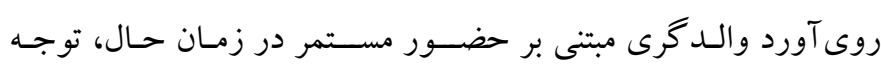

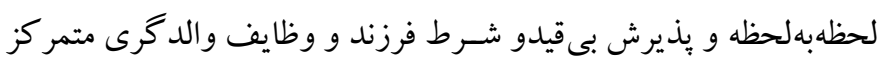

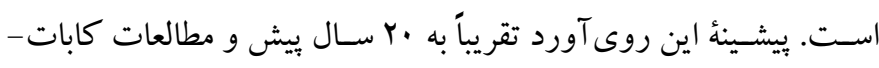

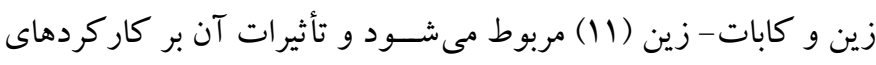

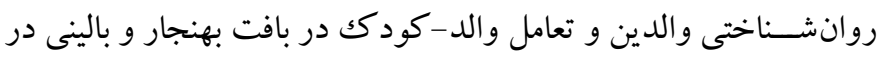
كود كان با طيفى از مشكلات روانشناختى و داراى كم توانى اخيراً مورد

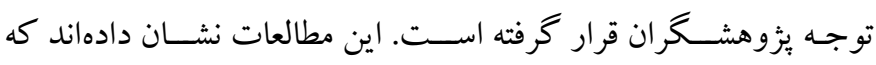

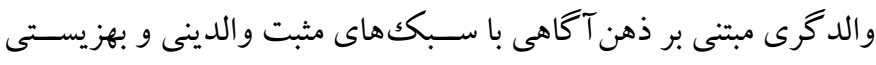

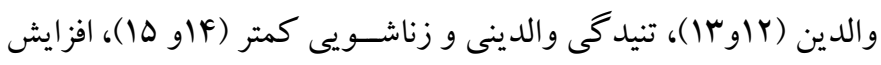

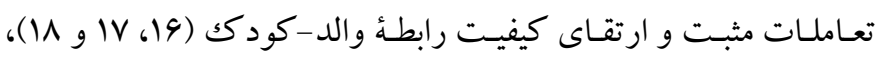
كاهش مشـكلات روانشناختى و ارتقاى سازش يافتكى روانى در والدين و فرزندان ارتباط دارد (19 و ع (1).

1. Parenting

2. Stress 
تأثير هر گونسه مـداخلـهُ فردى يـا گروهى مســتلزم به كار گيرى نيروها و

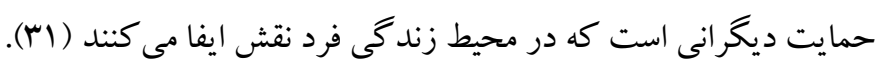

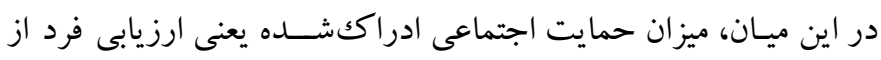

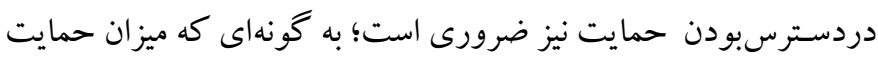

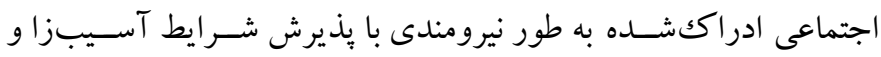

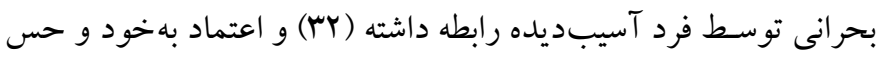

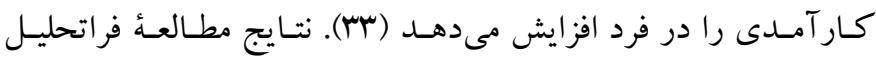

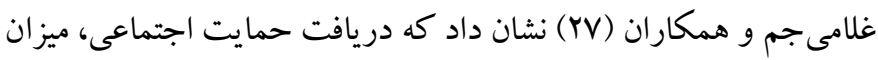

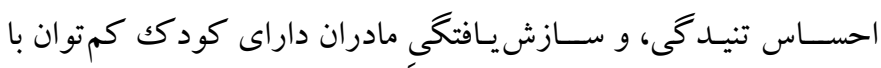
مادران بدون كودكى كمتوان تفاوت دارد.

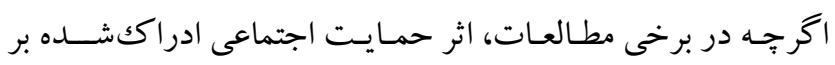

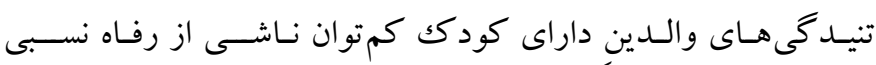

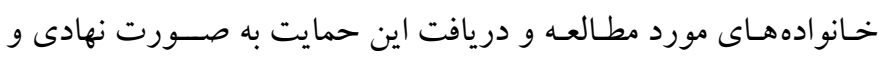

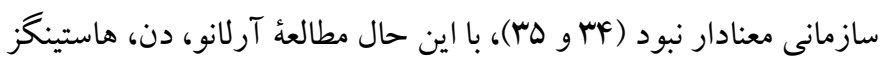
و هيوجس (Yr) نشـان داد احسـاس نياز كم به حمايت عاطفى، رضـايت

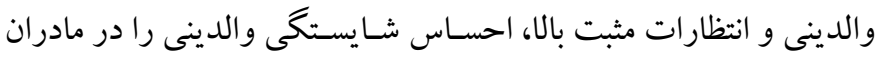

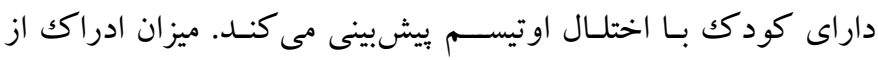

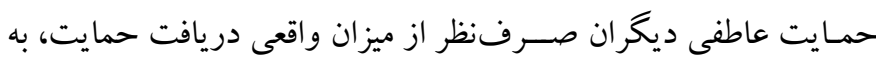

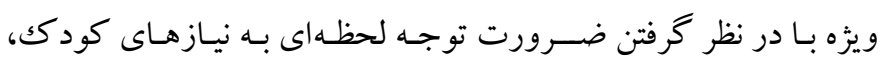
يذيرش واقعيت خود و فرزند داراى كم توانى در مادران به عنوان مر اقبان

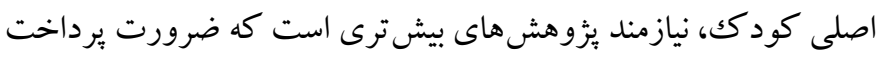

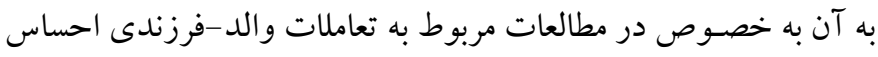

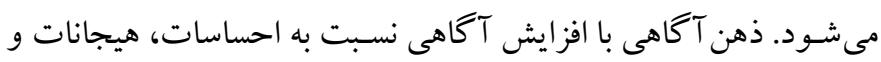

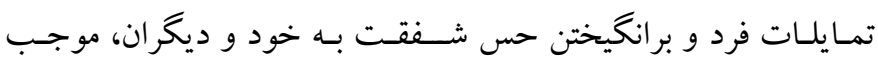

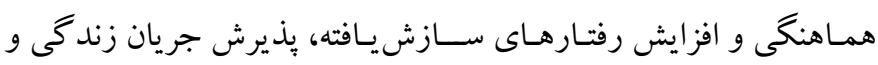
نخرش دلسوزانهُ فرد در ارتقاء رفتارهاى فردى و بين فردى وى در در ارتباط با ديخران شود (4).

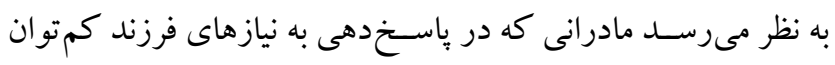
خود هميشـه در دسترس و حاضرند، به هيجانات و احساسات فرزندشان

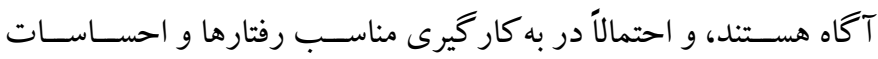
متناسـب با خواسـته هاى فرزندشـان مهارت دارند و خود را كار آمدتر و
مادران را مشغول نخَرانىهاى حاصل از داشتن اين فرزندان كرده و توجه لحظهاى به نيازهاى اين كود كان را كمتر مى كند.

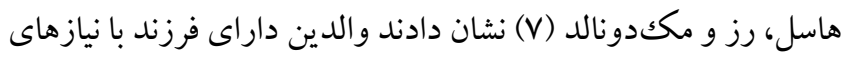

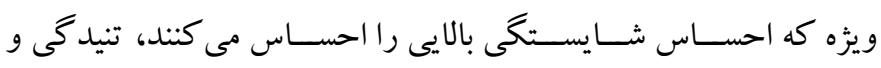

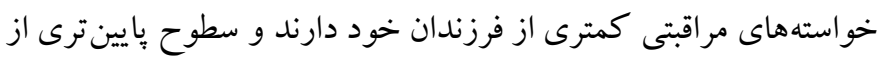

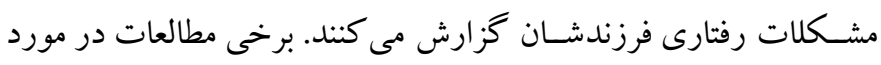

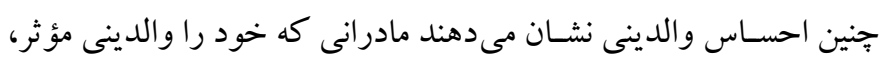

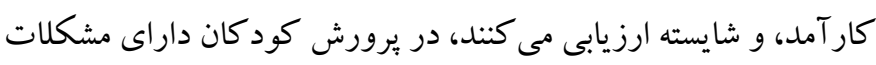

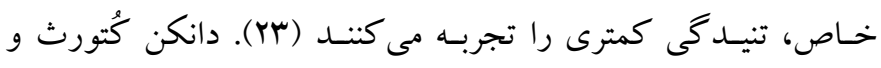

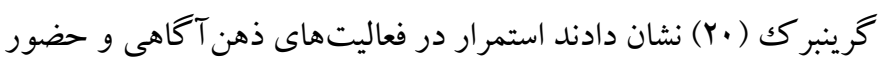

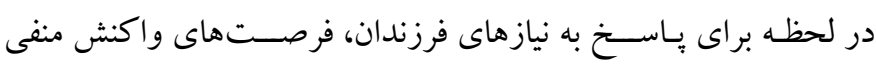

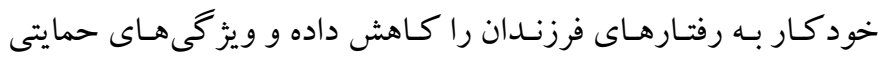

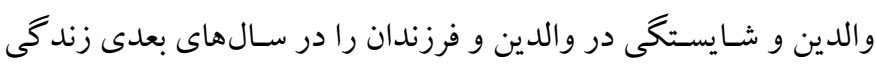

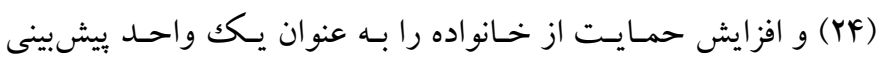

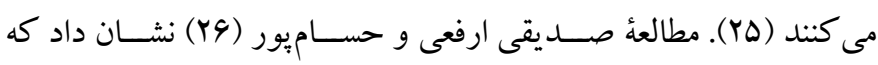

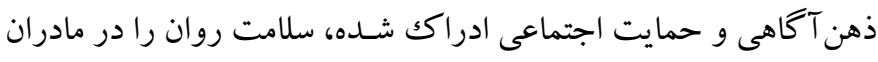
داراى كود كان كم توان ذهنى بيشبينى مى كند. دريافت حمايت اجتماعى از ديخرانى كه فرد به آنها علاقهمند است يا يان

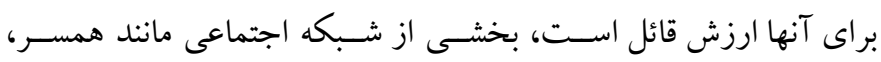

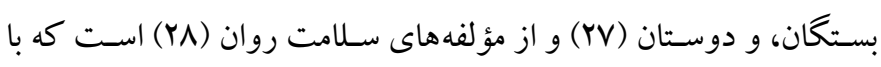

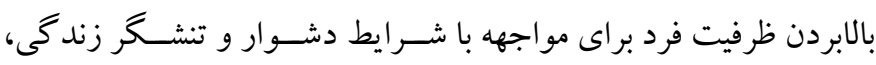

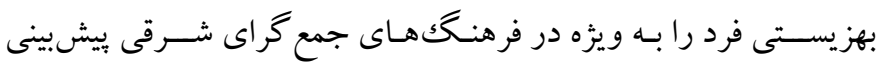

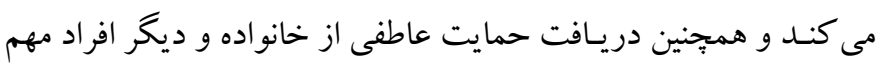

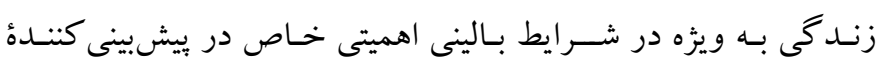
شــاخص هـاى بهزيسـتى در مادران داراى كود كان با نيازهاى ويزٔه ييدا

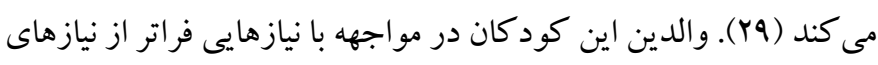

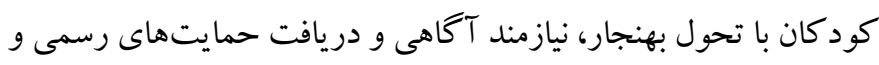

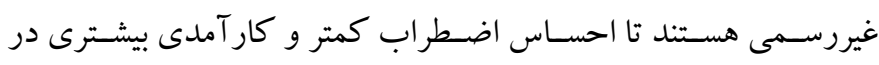

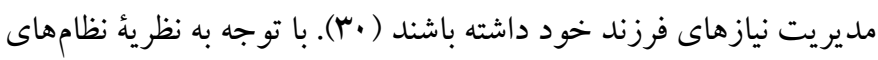

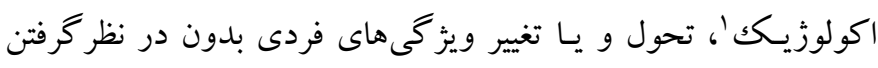

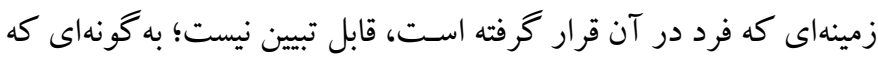

1. Ecological systems theory 
شــركت در بزوهش از مر اكز عمومى شـهـر مانند بار ككها، ســالنهاى

$$
\text { ورزشى، و مر اكز خريد انتخاب شدهاند. }
$$

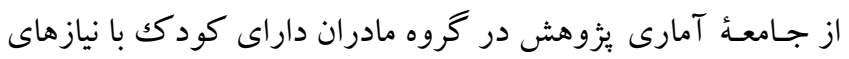

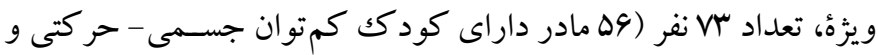

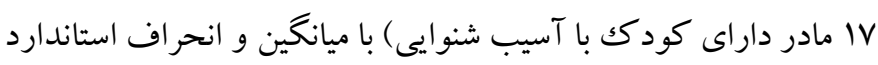

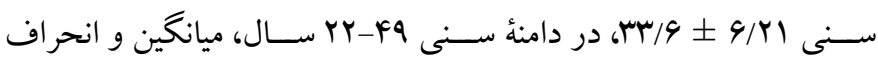

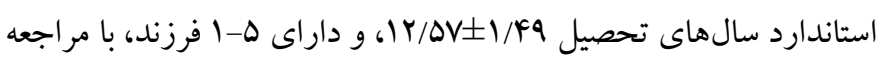

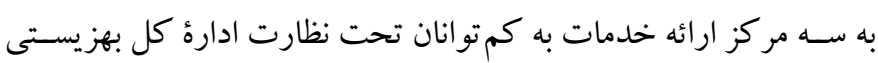

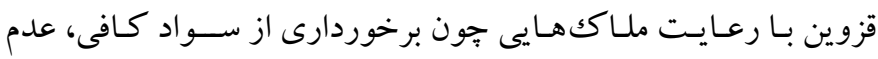

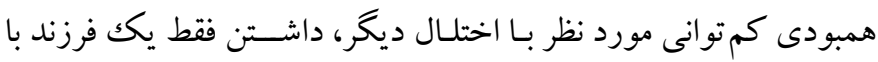

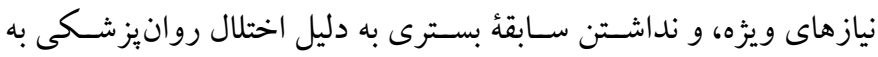

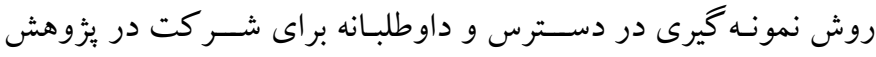

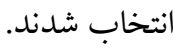

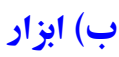

ا.مقياس ذهن آكاهى بينفردى در والسـرى ': مقيساس ذهن آكـاهى

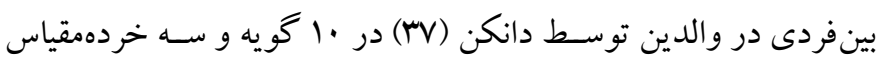

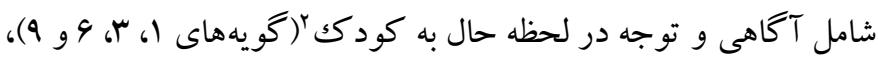
بازبودن و يذيرش بدون قضاوت" افكار و احساسات كود كان (كويههاى

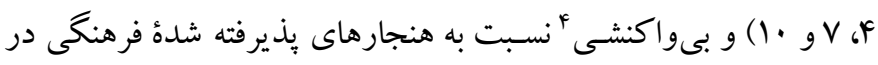

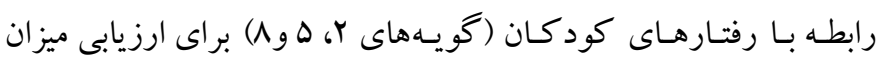
حضـور در لحظه و توجه به نيازهاى كود كك در مادران سـاخته شـــ. اين

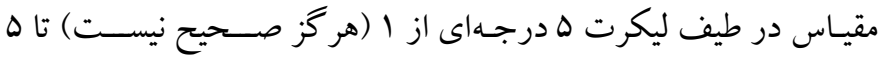

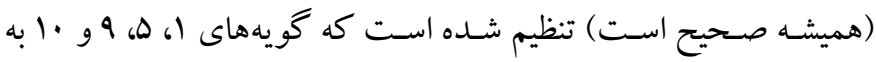
شــكل معكوس نمره كذارى مى شــوند. همة نمر ات خردهمقياس ها با هم

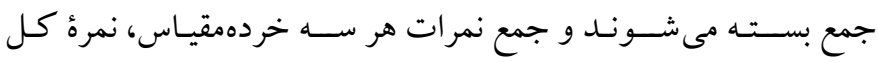

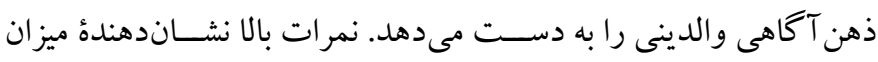

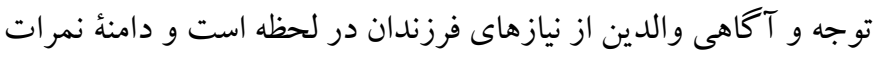

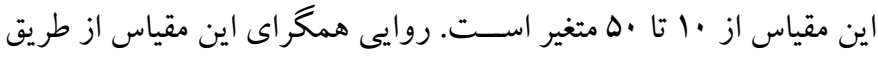

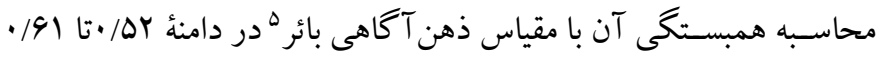

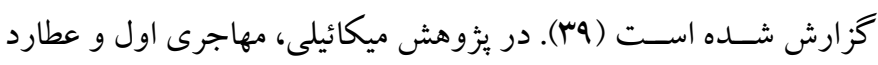

4. Non-reactivity

5. Baer
مؤثرتر ارزيابى مى كنند. از آنجايى كه بسـتر تعاملات والد-فرزند داراى

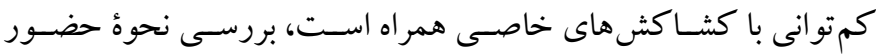

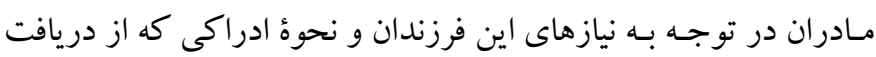

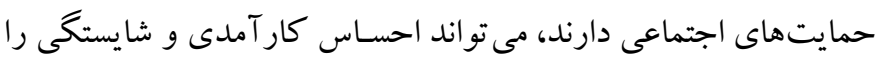

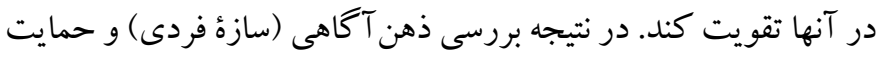

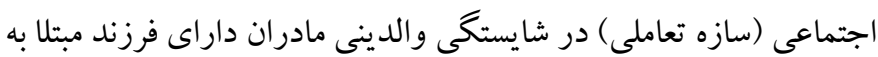

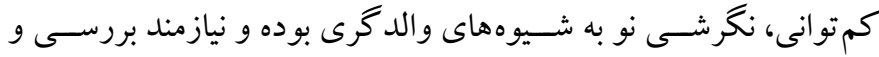

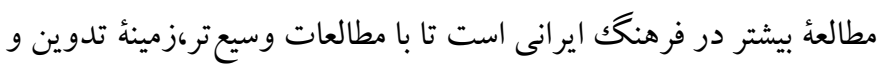

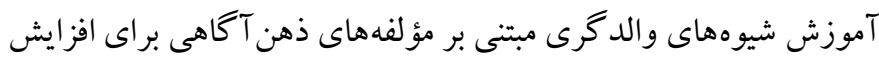

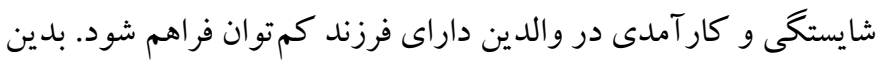

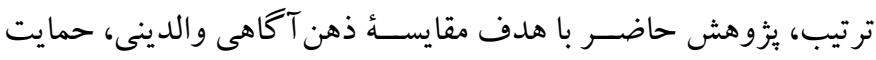

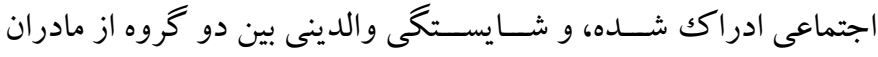

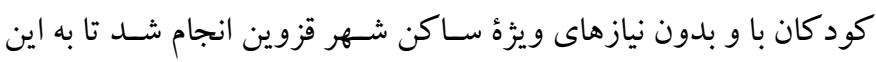

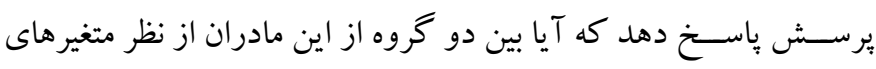
ذكر شده، تفاوت معنادارى وجود دارد.

روش الف) طرح هزوهش و شـــ كت كنند كان: روش ئزوهش توصيفى و از

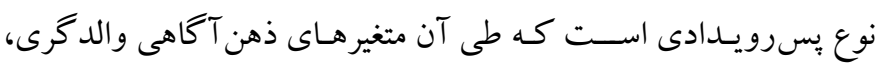

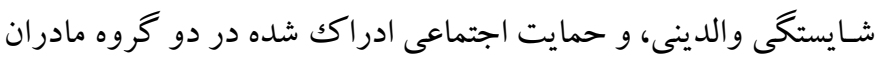
داراى كودكك باو بدون نياز ويزٔه مقايسه شـده است. جامعهُ آمارى اين يزّوهش دو گروه از مـادران داراى كودكك بدون نيازهاى ويزه و مادران داراى كودكك با نيازهاى ويزه ساكن شهر قزوين در سال VIr إبودند. از

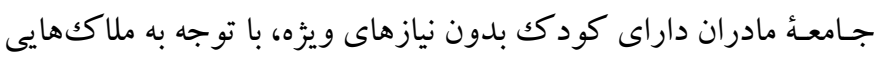

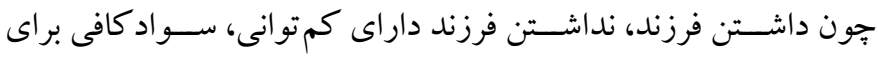

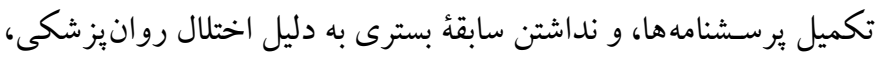

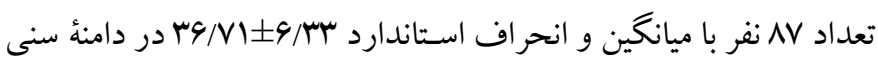
ه

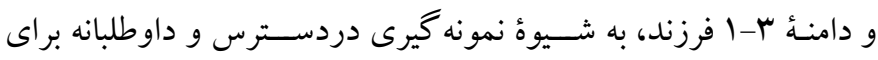

1. Interpersonal mindfulness in parenting (IM-P) scale

2. Awareness and present-centered attention

3. Non-judgment 
بين Y ا تا •و اســت كه نمرات بالا نشــان دهنده ادراكك زياد از حمايت اجتماعى اسـت كه فرد از سـوى خانواده، دوسـتان، يا ديخر افراد مهم در زنـدكى دريـافت مى كند. روايى واگر ایى اين مقياس با خردهمقياسهاى

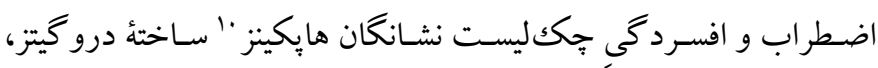

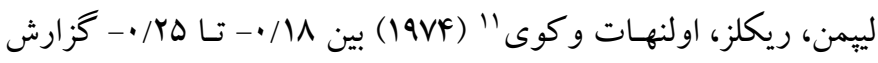
شــده اسـت (FY). در مطالعهُ ادواردز نيز (FY) اعتبار مقياس با اسـتفاده از

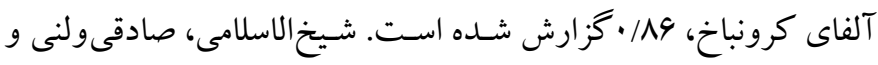
محمدى (FF) ضـريب آلفاى كرونباخ سه بعد حمايت اجتماعى دريافت

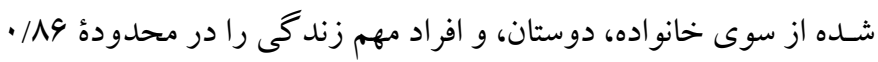
تـا •9/ • گزارش كردند. در اين بزٔوهش اعتبار ســه خردهمقياس حمايت

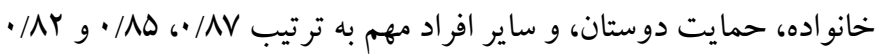
به دست آمد. ج) روش اجرا: پِ از اخذ مجوزهاى لازم از معاونت توانبخشى ادارهٔ كل بهزيستى استان قزوين براى ورود به سـه مركز توانبخشى كم تو توانان

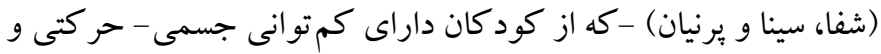
آسيب شـنو ايى نكهدارى مى كردند- با مديران و كارشـناسان اين مراكز

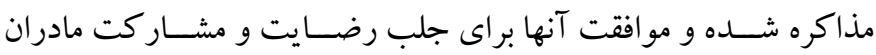

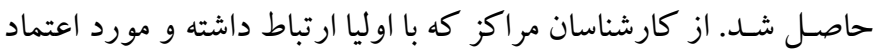
آنها بودند، خواسته شد تا هدف ئزوهش را براى مادران توضيح دهند و

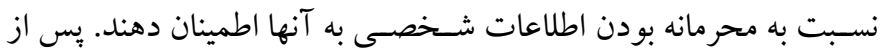
توضسيح هدف يزوهش و جلب مشار كت و رضايت مادران براى شر كت

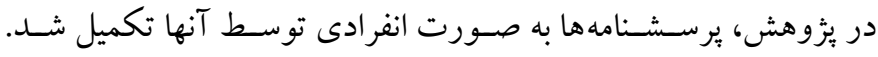

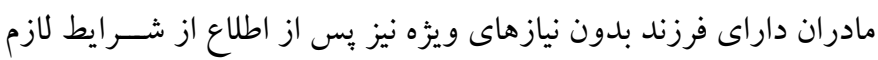

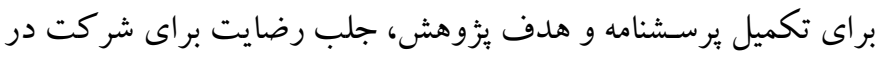
مطالعه، و اطمينان يافتن از محرمانه بودن اطلاعات، به سوالات يرسشنامهها

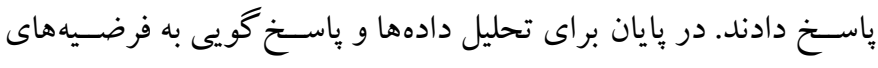

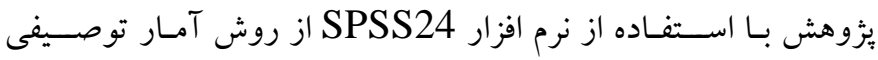

7. Family support

8. Friend support

9. Significant-other support

10. Hopkins symptom checklist (HSCL)

11. Derogatis, Lipman, Rickels, Uhlenhuth, and Covi

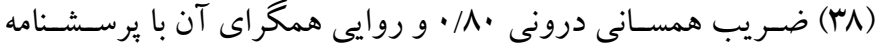

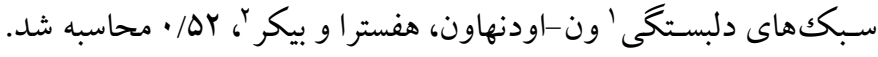
در اين يثوهش، اعتبار مقياس با استفاده از آلفاى كرونباخ IVI· • به دست Tمد

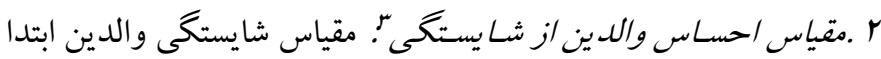
توسط گيبود-و الستون و واندرسمن (q) در انجمن روانشناسى آمريكا براى ارزيابى ميزان شـايستخى و كار آمدى والدين در موضوع والدگرى در IV كويه با طيف ليكرت 9 درجهاى تهيه شـد. ستبس جانستون و ماش

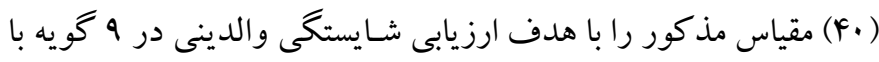
طيف ليكرت 9 درجـهاى از كـاملاً مخالفم (9) تا كاملاً موافقم (1) تنظيم كردند. بر اي محاسبة نمر ات شايستكى والدين، همه نمرات ه گويه با هم جمع بسـته مى شـوند و دامنهُ نمرات بين 9 تا هF اسـت. نمرات بالا در اين مقياس، منعكس كنندهُ شـايســـى و كار آمدى والدين در رابطه با فرزند اسـتـ. روايى واكراى اين مقيـاس بـا جـك ليسـت مشـكــات رفتارى

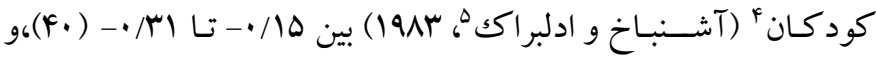
اعتبار آن با استفاده از آلفاى كرونباخ توسط رشيد و حسينى اصل نظرلو

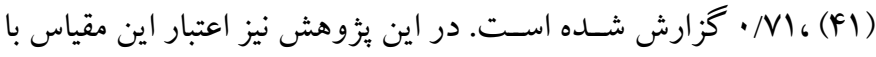
استفاده از آلفاى كرونباخ V9/ • به دست آمد.

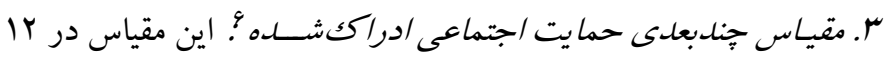

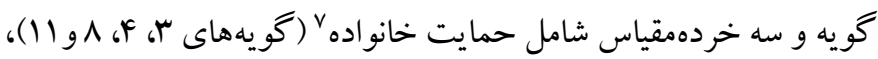

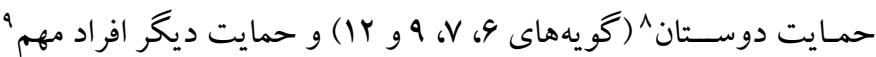

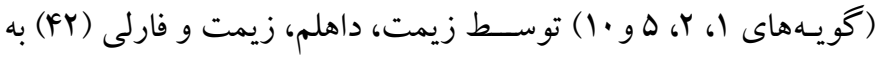
منظور سـنجش حمايت اجتماعى ادراكك شـده از طرف خانواده، دوستان و افراد مهم زندكى فرد در طيف ليكرت ه درجهاى از كاملاً مخالفم (1) تا كاملاً موافقم (ه) ساخته شده است. نمرات افراد در هر سه خردهمقياس جمع شده و ميزان حمايت ادراكك شده در هر حيطه را نشان مىدهد و از مجموع نمرات هرســـه خردهمقيـاس، نمرهُ كـل فرد و ميزان حمـايـت اجتماعى ادراكك شـد كل به دست مى آيد. دامنهُ نمرات كل اسن مقياس

1. Attachment styles questionnaire (ASQ)

2. Van Oudenhoven, Hofstra, and Bakker

3. Parenting sense of competence scale (PSOCS)

4. Child Behavior checklist (CBCL)

5. Achenbach and Edelbrock

6. Multidimensional scale of perceived social support 


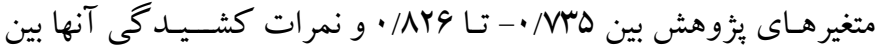

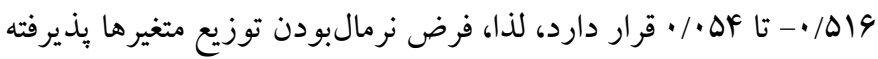

$$
\text { مىشود. }
$$

(ميانخين و انحر افاستاندارد) و اسـتنباطى (مقايسه خروههاى مسـتقل و تحليل واريانس جندمتغيره) استفاده شد.

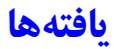

با توجه به ملاكك معمول براى ارزيابى نرمالبودن دادهها بر اسـاس كجى

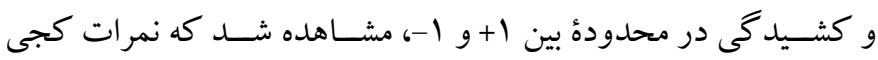

جدول ا: ميانكين و انحرافاستاندارد نمرات دو كروه از مادران كودكان با و بدون نيازهاى ويزه در متغيرهاى يزوهش

\begin{tabular}{|c|c|c|c|c|c|c|c|}
\hline \multirow{2}{*}{ دامنهُ مشاهده شده نمرات } & \multicolumn{2}{|c|}{ كل } & \multicolumn{2}{|c|}{ 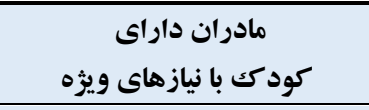 } & \multicolumn{2}{|c|}{ 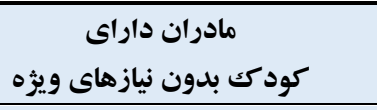 } & \multirow[t]{2}{*}{ كروهها } \\
\hline & استاندارد اف اف & ميانكين & انحراف استاندارد & ميانگين & انحر اف استاندارد & ميانتين & \\
\hline$I T-F V$ & $\Delta / V Y$ & $\mathrm{Tr} / \mathrm{GV}$ & $0 / 99$ & $M T / 9 Y$ & $\Delta / \Delta Q$ & mi/qr & ذهن آكاهى والدگرى( كل) \\
\hline $9-19$ & $r / V r$ & $I T / V A$ & r/VF & Ir/Tr & $r / V$ & $1 \% / \Delta$ & آكاهى و توجه در لحظه \\
\hline$r-10$ & $r / r$ & 1.119 & r & $1 \cdot / V r$ & $r / F \Delta$ & $9 / 99$ & بازبودن و يذيرش بدون قضاوت \\
\hline$r-10$ & $r / I V$ & $9 / V Y$ & $r / r q$ & 1.1 .4 & $1 / 90$ & $Q / F F$ & بىواكنشى نسبت به رفتارهاى كود دك \\
\hline $\mid f-\Delta f$ & $\Lambda / \Delta G$ & ra/l & $1 / 19$ & $r 4 / 94$ & $\Lambda / V r$ & $r V / r F$ & شايستخى والدينى \\
\hline $19-\lambda F$ & If/VQ & $09 / 94$ & $\mid r / r \Lambda$ & $\Delta \Delta / \Delta \varphi$ & ID/Ar & $\Delta V / \Delta q$ & حمايت اجتماعى (كل) \\
\hline$r-Y \Lambda$ & $\Delta / 9 r$ & $r \cdot 194$ & $\Delta / \Delta \Lambda$ & $r \cdot / r \Delta$ & $9 / 41$ & $r \cdot / 9 r$ & حمايت عاطفى خانواده \\
\hline$r-Y \wedge$ & 91.9 & $19 / 4$ & $4 / 11$ & $\mid \Delta / \Delta F$ & ه/৭४ & IV/TY & حمايت عاطفى دوستان \\
\hline \multirow[t]{2}{*}{$\varphi-r \wedge$} & $\Delta / 9 \Lambda$ & $19 / 9$ & $\Delta /{ }^{\prime} \Lambda$ & $19 / 94$ & $9 / F V$ & $19 / 09$ & حمايت از طرف افراد مهم \\
\hline & \multicolumn{2}{|c|}{19.} & \multicolumn{2}{|l|}{$v^{r}$} & \multicolumn{2}{|l|}{$\Lambda V$} & تعداد مادر ان شر كت كننده \\
\hline
\end{tabular}

شاخص تحمل '، و عامل تورم واريانس بَنز بررسى شد و از آن جايى كه

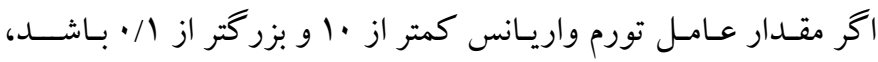

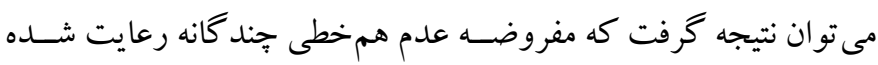

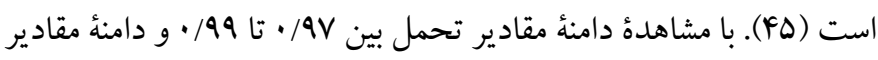

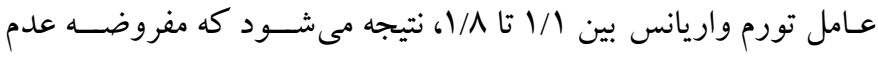
هم خطى جند گانه در اين مطالعه برقرار است.

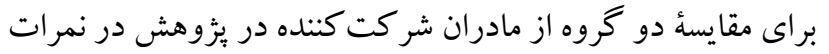

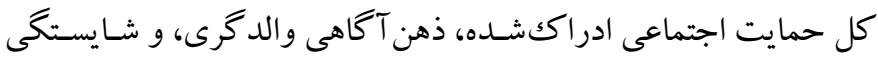

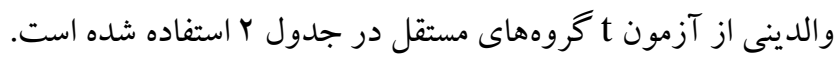

3.Variance inflation factor (VIF)
جدول انشـان مىدهد كه نمرات ذهن آكاهى والدگرى در مادران

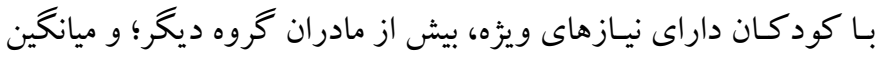

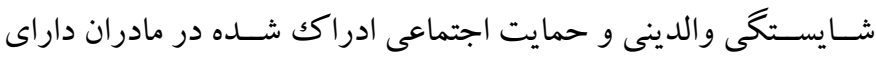
فرزنــــــدون نيـازهاى ويزه، بيش از مادران داراى فرزند با نيازهاى ويزه

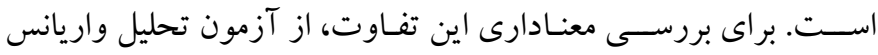

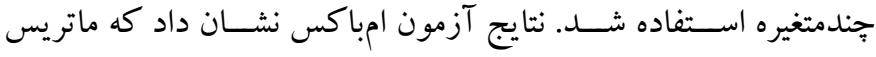

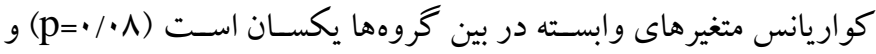

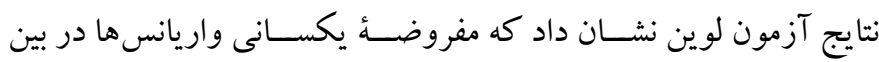

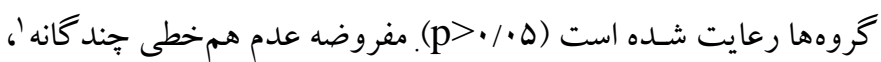

1.Multicolinearity

2.Tolerance 
جدول r ب آزمون t براى مقايسة دو كروه در نمرات كلى متغيرهاى ثزوهش

\begin{tabular}{|c|c|c|c|c|c|}
\hline خطاى استاندارد & تفاوت ميانكين & سطح معنادارى & درجه آزادى & $\mathbf{t}$ & نمرات كل متغيرها \\
\hline$r / r F$ & $r / r$ & $\cdot / \mu \Lambda$ & 101 & $\cdot / 14$ & حمايت اجتماعى ادراكك شده (كل) \\
\hline $1 / \mu 4$ & $r / 9 V$ & $\cdot / \cdot f$ & 109 & $1 / 99$ & شايستكى والدينى (كل) \\
\hline$\cdot / 19$ & $-r / r q$ &.$/ \cdot 1$ & 101 & $-r / \Delta 9$ & ذهن آكاهى والد گرى(كل) \\
\hline
\end{tabular}

نمرات هايين ترى در شايستخى و نمرات بالاترى در ذهن آكاهى والدگرى

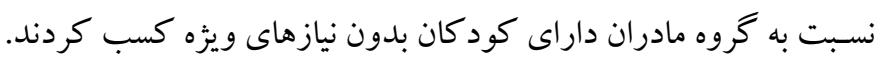

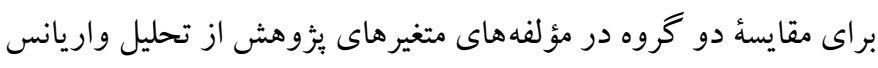

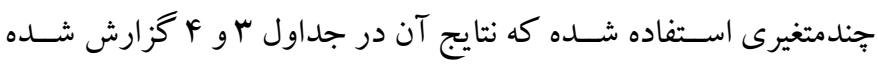

مقايسه نمرات كل متغيرهاى حمايت اجتماعى ادراكثشه، شايستخى

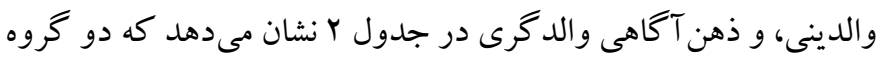

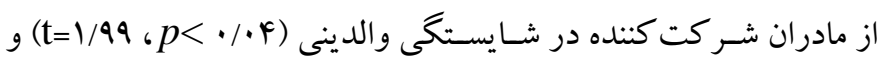

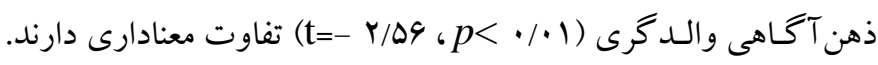
نتايج جدول ا نشـان مىدهد كه مادران داراى كود كان با نيازهاى ويزه،

است.

جدول r: تحليل واريانس جندمتغيرى نمرات افراد در متغيرهاى يؤوهش

\begin{tabular}{|c|c|c|c|c|c|c|c|}
\hline اندازه اثر & سطح معنادارى & $\mathbf{d f}_{r}$ & $d_{1}$ & $\mathbf{F}$ & ارزش & آزمون & منبع \\
\hline$\cdot / \cdot \wedge \mathrm{V}$ & $.1 . \Delta$ & $10 r$ & $v$ & $r / . \Delta$ & $\cdot / \cdot A V$ & اثر ييلاى & \multirow{4}{*}{ كم توانى كودك } \\
\hline$\cdot / \cdot A v$ & .1 .0 & 1Qr & v & $r / . \Delta$ &.$/ 91$ & لامبداى ويلكز & \\
\hline$\cdot / A v$ &.$/ . \Delta$ & $10 \mathrm{r}$ & v & $r / . \Delta$ & .1 .90 & اثر هاتلينك & \\
\hline$\cdot / \cdot A v$ & .1 .0 & $10 r$ & v & $r / \cdot \Delta$ & .1 .90 & بزر گترين ريشه رى & \\
\hline
\end{tabular}

F( IOY،V)=

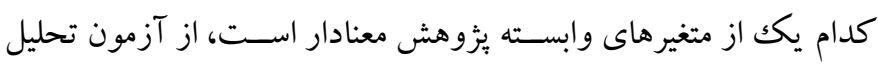
واريانس استفاده شد (جدول F).

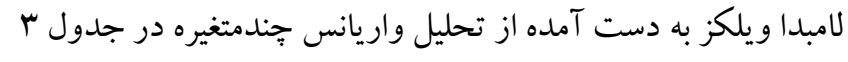
نشـان مىدهـد كـه تـأثير وجود كودكى داراى نيـازهاى ويزه بر تركيب

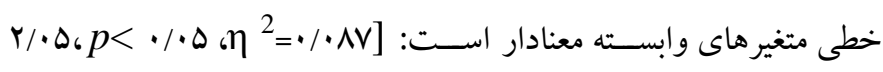

جدول ع: تحليل واريانس نمرات دو كروه از مادرانِ كودكان با و بدون نيازهاى ويزَه در مؤلفههاى ذهن آكاهى، حمايت عاطفى، و شايستكى والدينى

\begin{tabular}{|c|c|c|c|c|c|}
\hline مجذور اتا & سطح معنادارى & Foر آ & ميانكينمجموع مجذورات & & \\
\hline.$/ \cdot 1 r$ & $\cdot / / f$ & $r / 10$ & $10 / 94$ & حضور در لحظه (ذهن آكاهى) & \\
\hline.$/ \cdot \Delta$ & 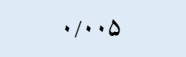 & $\Lambda / Y \Delta$ & Fr/Tr & مؤلفه بازبودن (ذهن آكاهى) & \\
\hline.$/ \cdot r$ & $\cdot / \cdot v$ & r/4G & $10 / V$ & مؤلفه بىواكنشى (ذهن آكاهى) & \\
\hline$\% r$ & $\cdot 19$ & 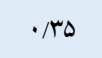 & IY/KY & حمايت عاطفى خانواده & اثر كم توانى فرزند \\
\hline.$/ \cdot 1 \mathrm{~V}$ & $\cdot / 1$ & $r / 99$ & $99 / \cdot 4$ & حمايت عاطفى دوستان & \\
\hline$\cdot / \cdots \cdot 1$ &.$/ 91$ &.$/ \cdot 1$ & $\cdot / \& \Delta$ & حمايت عاطفى افراد مهم & \\
\hline 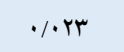 & $\cdot / \cdot \Delta$ & $r / 99$ & $r q 4 / . q$ & شايستكى والدينى & \\
\hline
\end{tabular}

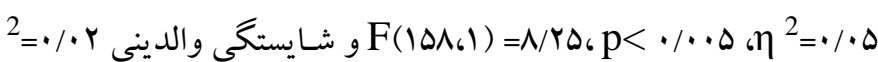
م تفاوت در حمايت عاطفى از طرف دوسـتان از لحاظ آمارى معنادار نبود

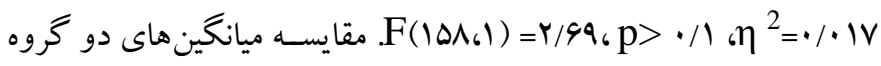

F به دست آمده از تحليل واريانس نمرات دو گروه از مادران داراى

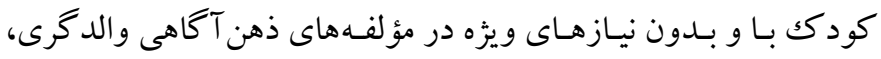

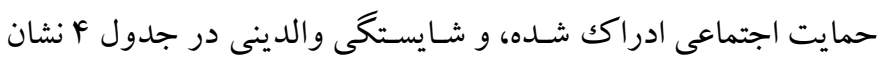

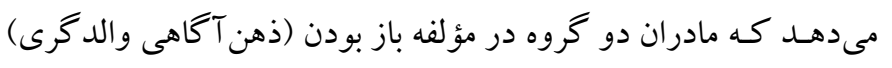


نسـبت به بدران در اين مؤلفه نمرات بالاترى كسـب كردند، جون اوقات

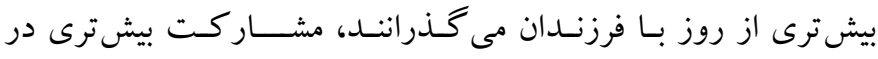

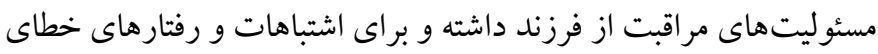

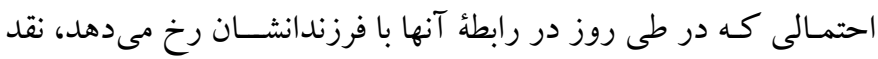

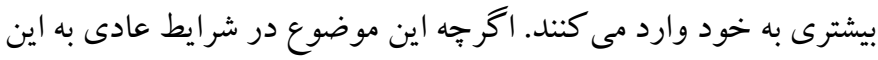

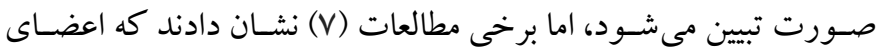

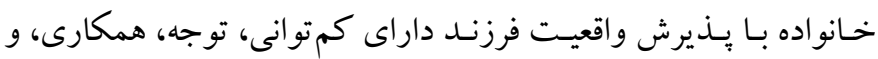

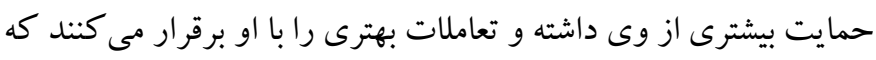

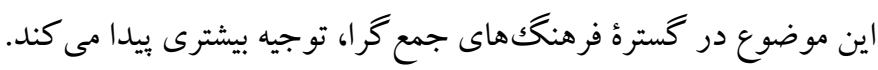

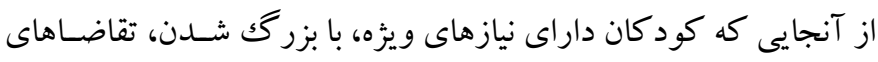
جـديـدى بر مـادران تحميـل مى كنـــ، توجه لحظهاى و مراقبت آكًاهانه

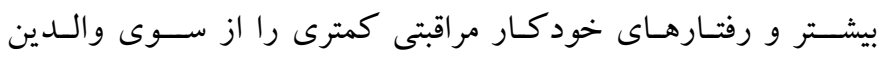

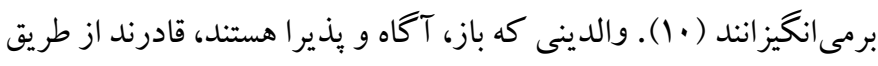

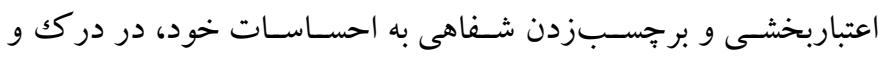
وضوح بخشى به احساسات خود و حل مسئله، كار آمدتر عمل كنند؛ اين

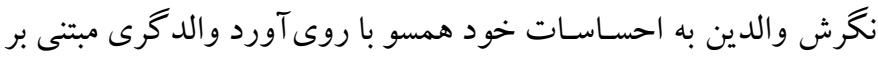

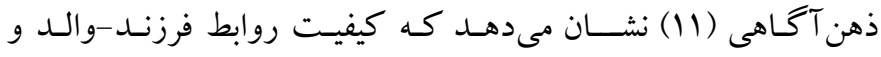

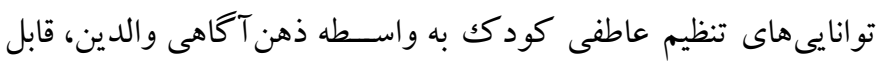

$$
\text { بهبود است (1)، IV و (1). }
$$

نتايج بزُوهش همجنين حاكى از بالا بودن نمرات آكاهى و توجه در

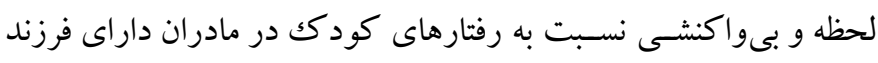

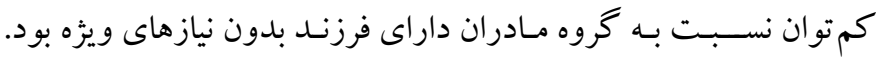

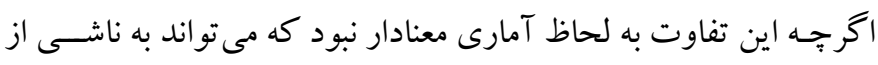

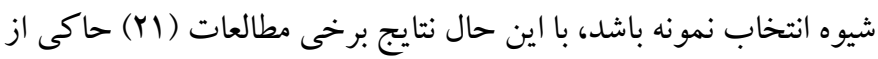

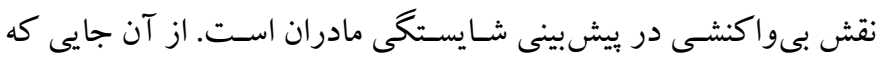

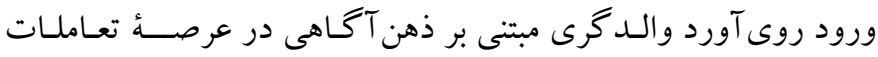

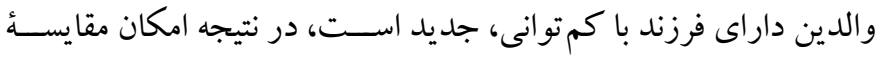

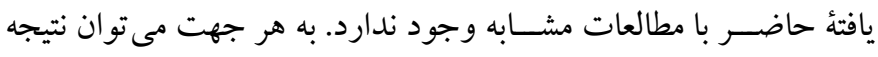

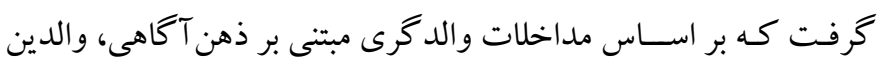

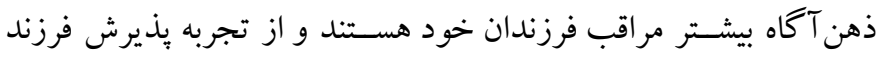
برخوردارند و در نتيجه به شيوهاى مؤثرتر با كشاكش هاى والدخرى هرد كنار
در جـدول ا نشــان مىدهـد كـه مادران داراى كود كك با نيازهاى ويزه،

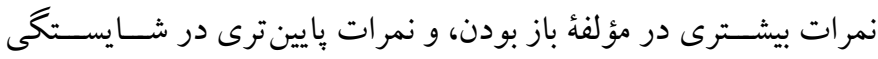
والدينى نسبت به مادران داراى كودكك بدون نيازهاى ويزه داشتند.

\section{بحث و نتيجه كيرى}

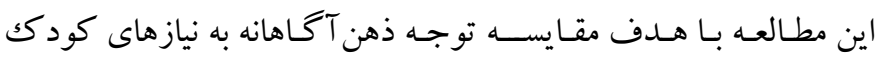

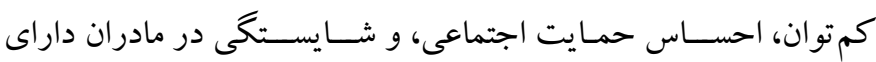

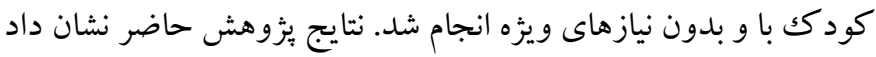

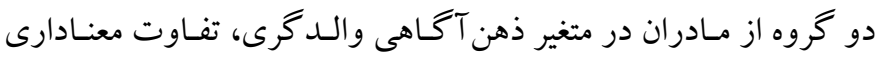

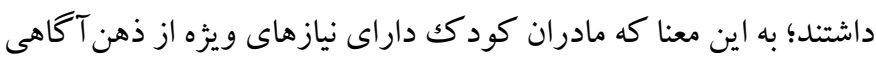

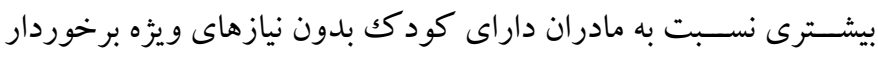

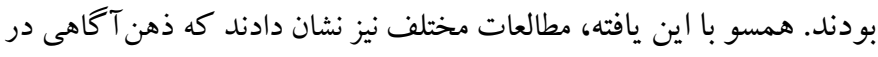

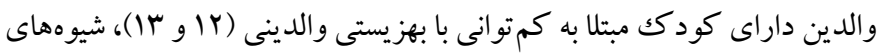

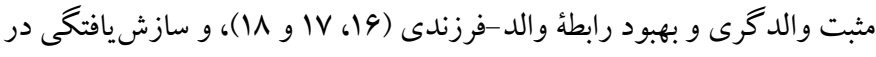
رابطةُ والـد-فرزنـدى ارتبـاط دارد (19). برخى يزووهش هـا همســو بـا يـافته

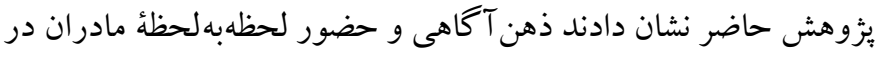
توجـه به نيازهاى فرزندان كمتو انشــان، موجب توجه فاقد قضسـاوت و و

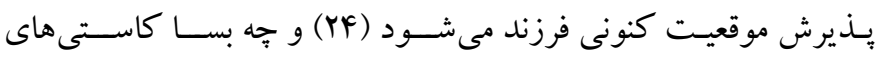

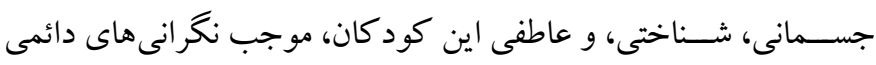

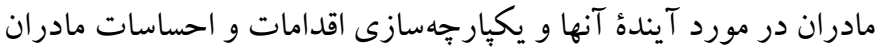

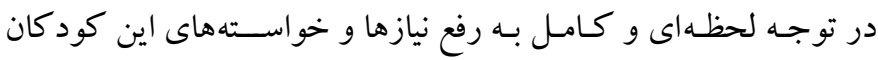
مىشـود. اين والدين به طور معمول نسـبت به نيازهاى كودك كم تو توان

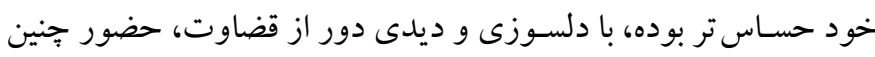

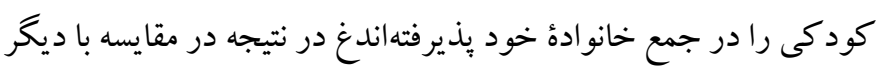

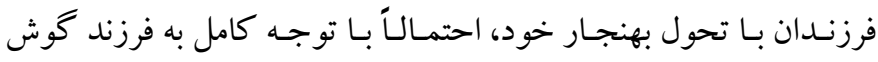

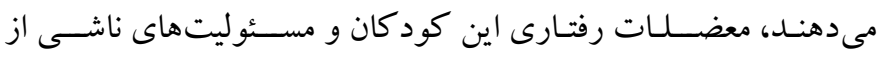
والدگرى آنها را يذيرفته، و با كسترش آكاهى از هيجانات و و احساسات

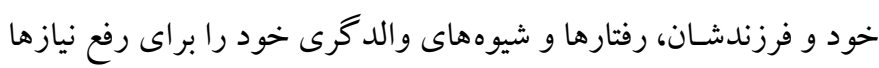

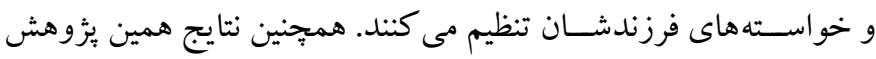

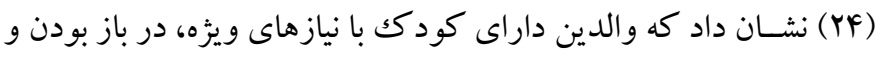

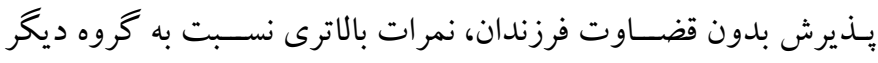

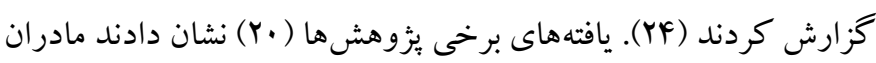




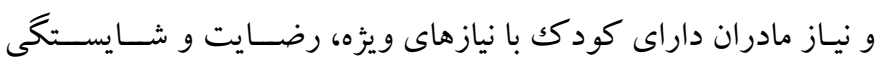

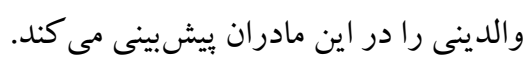

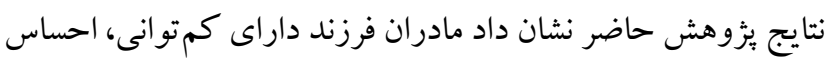

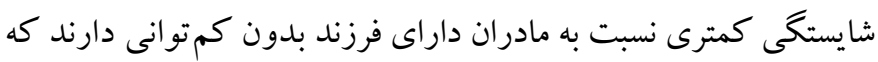

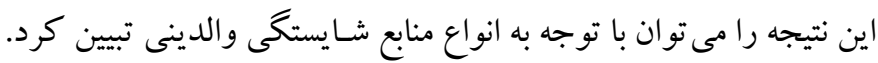

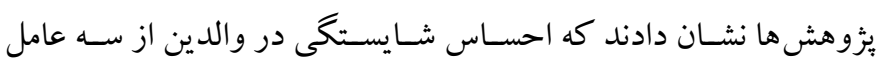

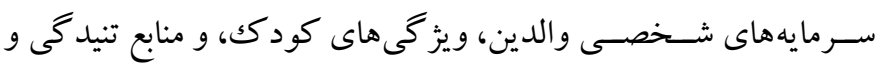

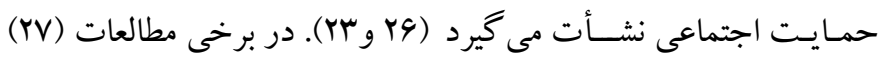
مشخص شد كه ميزان حمايت اجتماعى از مادران با باسخدهى و استفاده

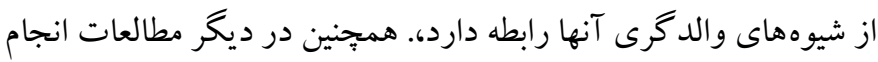

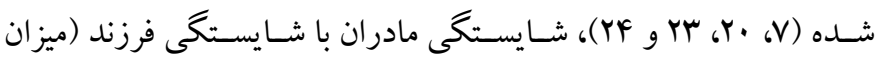

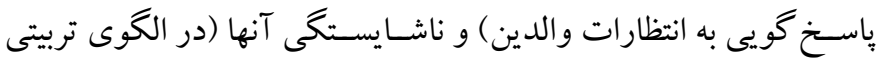

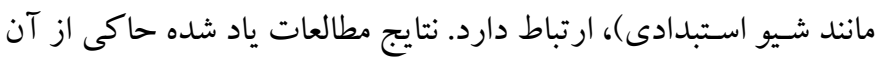

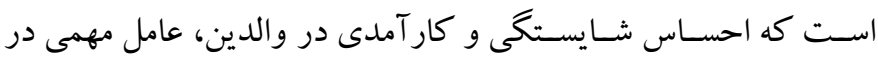

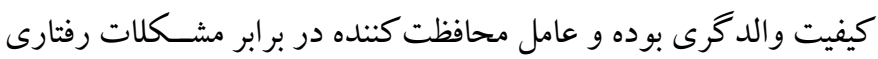

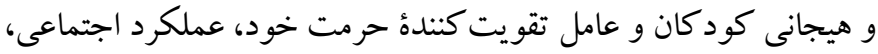
و تحصيلى فرزندان به شمار مىرود. مطابق با اين مطالعات، فشار ناشى از

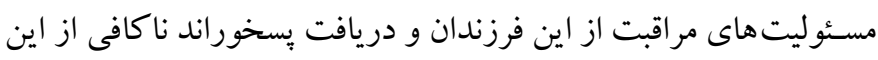
فرزندان در تناسـب با انرزى صـرف شـده، احساسى از ضعف كفايت در

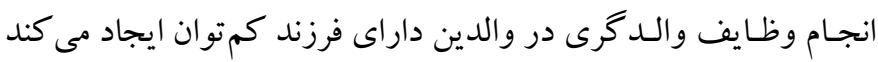

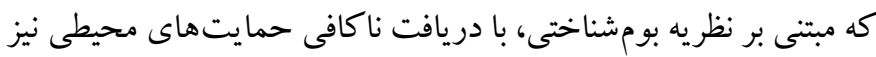
تقويت شود.

كود كان داراى نيازهاى ويزه با طيفى از كمتوانىهاى مختلف، يكى از خروههـاى محروم و حـاشــيهاى هر جامعهاى هســتند كه روزانه از

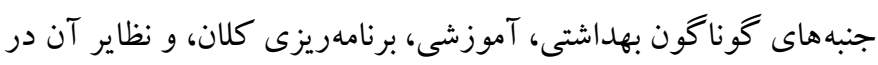

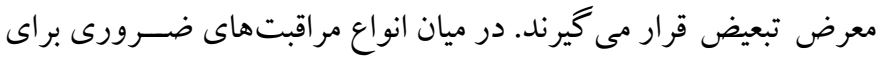

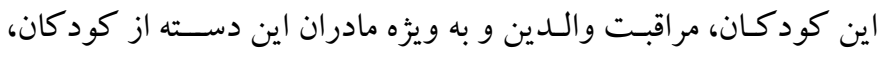

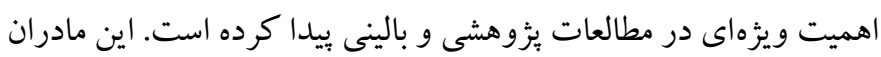

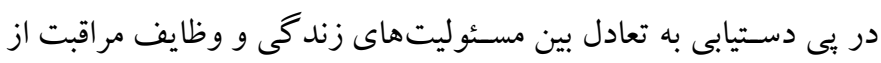

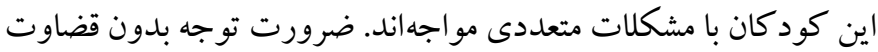
و يـــيرش واقعيـت فرزند داراى كم توانى موجب تمركز بر الكويى نوين

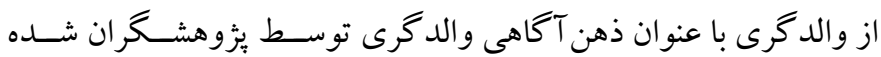

آمده و واكنش هاى منفى بيشـترى به اين معضــلات نشــان مى دهند (11)

نتايج اين يثزوهش همجنين نشـان داد مادران كود كان داراى نيازهاى

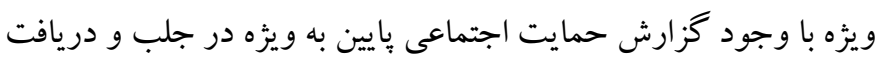
حمايت عاطفى از دوســان و آشـنايان نسـبت به مادران داراى كودك بـدون نـاتوانى، تفـاوت معنادار آمارى نداشــتند. همســو با نتايج برخى مطالعات مانند مطالعه شـكيب و هاشـمىرزينى (MF) مى توان نبود تفاوت معنادار در نمرات حمايت اجتماعى را به انتخاب نمونهُ با رفاه نسبى تفسير مانس

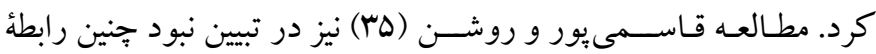

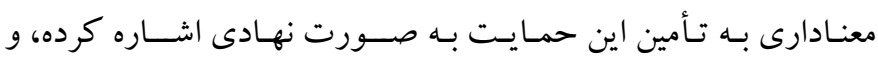

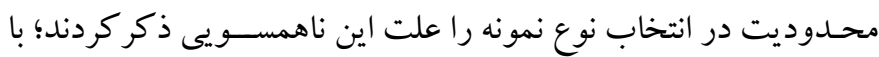

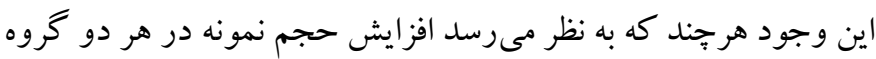

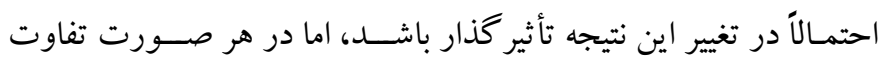
بالينى بين دو گروه نشان مىدهد مادران داراى كودك كم تو ان بان با وجود

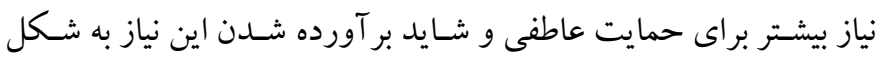
واقعى، ادراكك ضـعيف ترى از دريافت حمايت اجتماعى داشــتند. نتايج

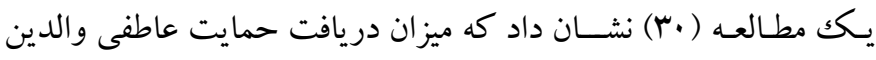

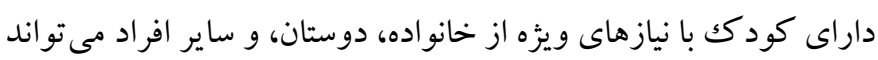
در كاهش نشانگان افسردگى، اضطراب، و تنيدگى در والدين مؤثر باشد إند

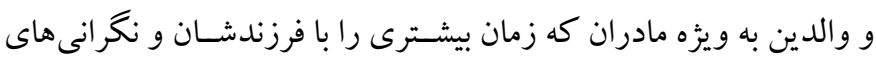

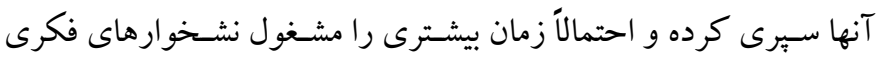

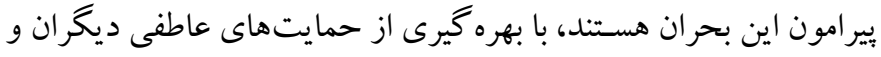

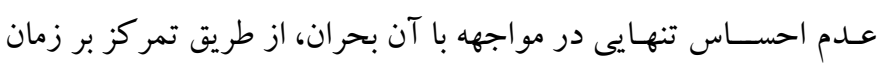

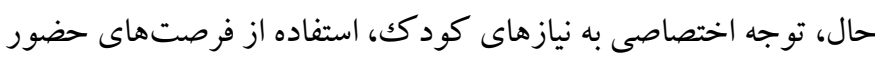
خود براى توجـه هشـيـارانهـ بـه خواســـهـهاى فرزندشــان، دغدغه ها و

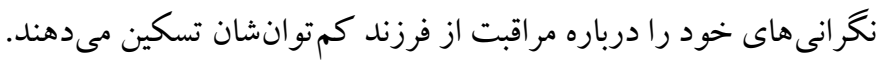
داشـتن ادراكى رضـايت بخش از حمايت دريافت شده از سوى ديخران،

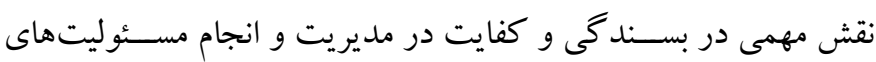

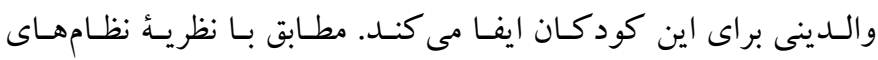

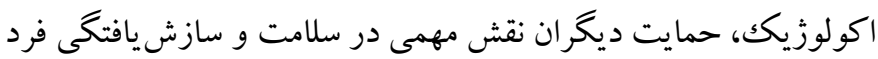

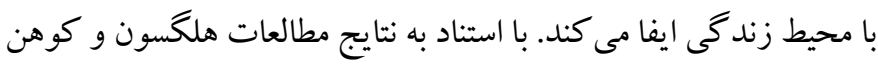

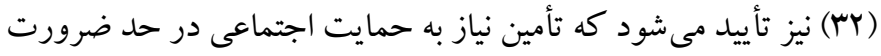


اثرات جندمتغيرى) انجام شـود تا بدين وسـيله در تبيين علّى و جندعاملى

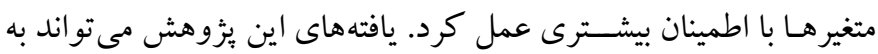

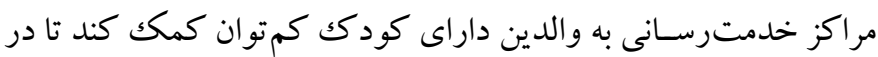

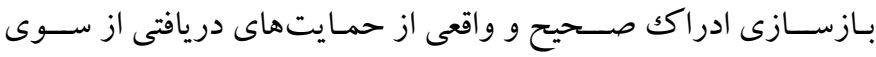

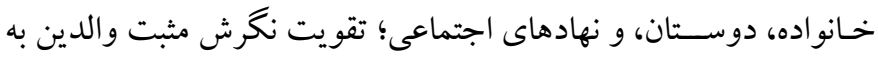

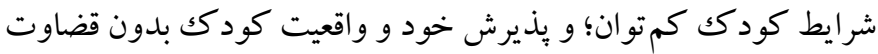
و ارزيابى، مؤثرتر و كار آمدتر عمل كنند. به طور كلى بر اساس يافتههاى

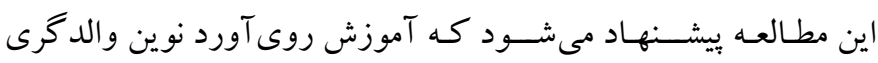

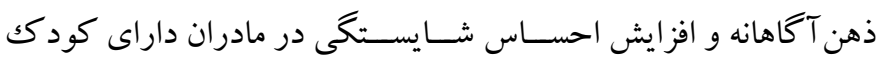
كمتوان، مورد تو جه و تأكيد قرار كيرد.

ملاحظات اخلاقى ييروى از اصـــول اخلـاقى بزوهش: اين مطالعه با رعايت كدهاى اخلاقى انجام

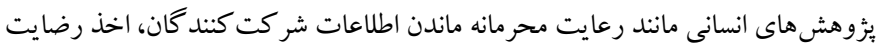

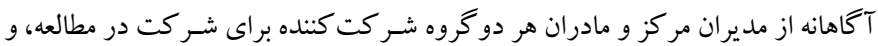

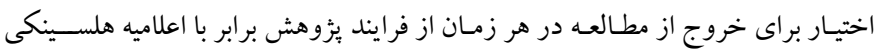
199.

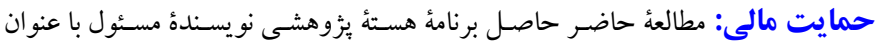

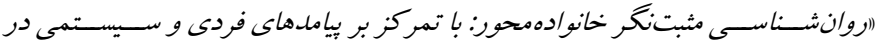

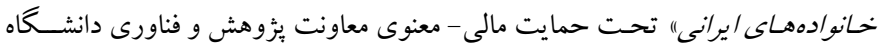

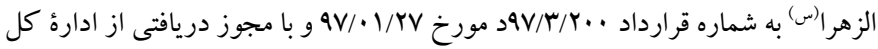

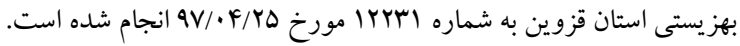
نقش نو يسند كان: نويسندة مسئول، مسئوليت انجام هماهنكى، اجر اى مطالعه، تجزيه و

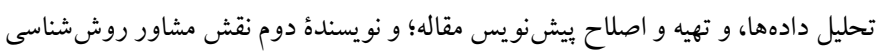
و تحليل آمارى مطالعه را بر عهده داشتند. تشكر و قدردانى: از مدير ان و برسـنل معاونت تو انبخشى ادارة كل بهزيستى استان

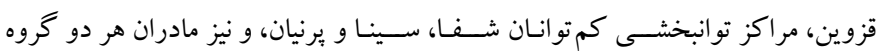

شر كت كننده در يزوهش براى همكارى و تسهيل در فرايند اجرا، قدردانى مى شو دو. تعارض با منافع: اين يثزوهش به طور مستقيم يا غيرمستقيم با منافع مالى يا حرفهاى هيج فرد يا سازمانى تعارض ندارد.
است. در جمعبندى يافتهاى يُزوهش حاضر مى توان گفت مادران داراى

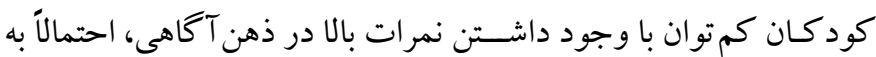

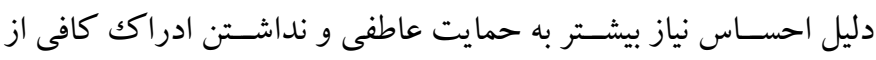

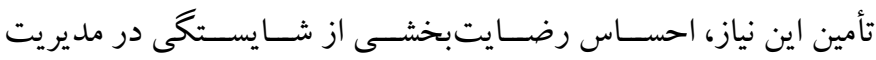
مسئوليتهاى مر اقبتى فرزندان خود نداشتند و به دليل نيازهاى فزايند اين

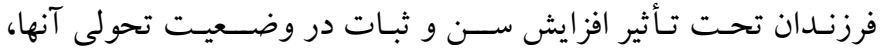
ناكار آمدى بيشـترى نيز احسـاس مى كنند؛ اين موضسوع مى تواند نمرات هايين شـايستّكى والدينى را در مادران داراى فرزند كم توان توجيه كند.

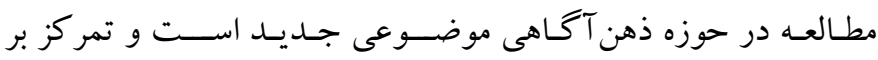

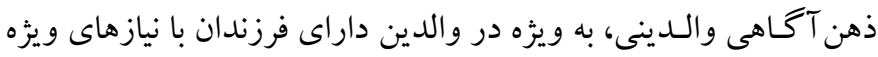
مى تو اند الكويى نوين از والدگرى در اين والدين به عرصهُ مطالعات ارائه

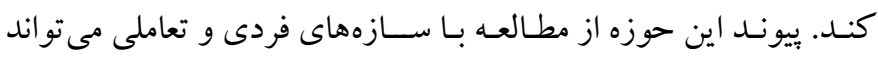

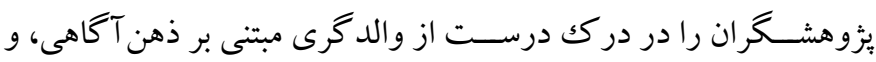

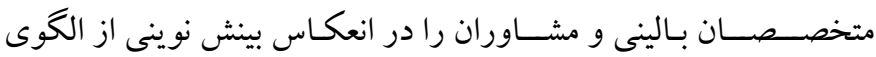

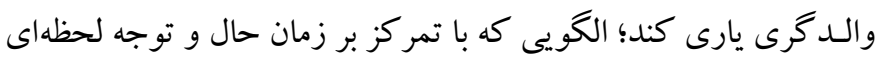

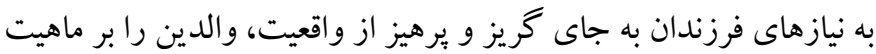

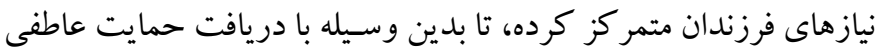

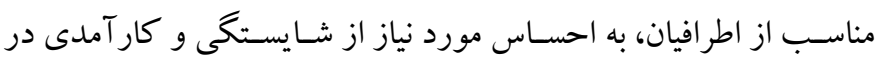
والدگرى دست ويدا كنند.

با توجه به محدوديتهاى بثزوهش حاضـر مانند عدم همكارى برخى از مراكز توانبخشسى افراد كم توان، انجام بزوهش فقط بر روى مادران،

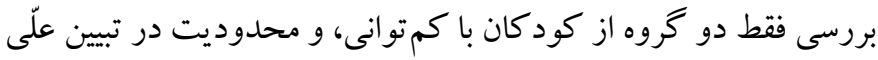

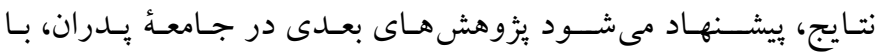

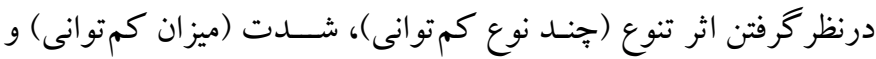

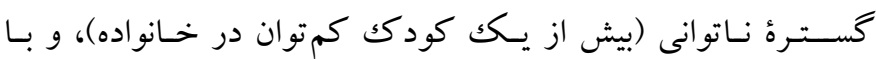

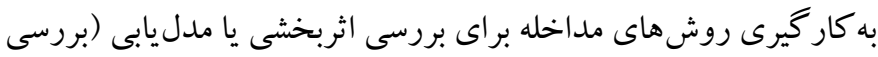




\section{References}

1. Raphael JL, Zhang Y, Liu H, Giardino AP. Parenting stress in US families: Implications for pediatric healthcare utilization. Child Care Health Dev. 2010; 36(2): 216-224. DOI: 10.1111/j.1365-2214.2009.010 52.x [Link]

2. Machalicek W, Lang R, Raulston, TJ. Training parents of children with intellectual disabilities: Trends, issues, and future directions. Curr Dev Disord Rep. 2015; 2(2): 110-118. https://doi.org/10.1007/s40474015-0048-4 [Link]

3. Sawyer MG, Bittman M, La Greca AM, Crettenden $\mathrm{AD}$, Borojevic N, Raghavendra, P, Russo R. Time demands of caring for children with cerebral palsy: what are the implications for maternal mental health? Dev Med Child Neurol. 2011; 53(4): 338-343. DOI: 10.1111/j.1469-8749.2010.03848.x [Link]

4. Whittingham K, Wee D, Sanders M, Boyd R. Predictors of psychological adjustment, experienced parenting burden and chronic sorrow symptoms in parents of children with cerebral palsy. Child Care Health Dev. 2013; 39(3): 366-373. DOI: 10.1111/j. 1365-2214.2012.01396.x. [Link]

5. Gupta VB. Comparison of parenting stress in different developmental disabilities. J Dev Phys Disabil. 2007; 19(4): 417-425. https://doi.org/10.1007/s10882-0079060-x [Link]

6. Lach LM, Kohen DE. Garner RE, Brehaut JC, Miller AR, Klassen AF, Rosenbaum PL. The health and psychosocial functioning of caregivers of children with neurodevelopmental disorders. Disabil Rehabil. 2009; 31(9): 741-752. DOI: 10.1080/096382 8080 2242163 [Link]

7. Hassall R, Rose J, McDonald J. Parenting stress in mothers of children with an intellectual disability: The effects of parental cognitions in relation to child characteristics and family support. J Intellect Disabil Res. 2005; 49(6): 405-418. DOI: 10.1111/j.13652788.2005.00673.x. [Link]

8. Anderson L, Larson SA, Wuorio A. 2010 FINDS National Survey."Assistive technology helps people with severe learning difficulties at night." 2001; Retrieved, 7. [Link]

9. Parkes J, White-Koning M, McCullough N, Colver A. Psychological problems in children with hemiplegia: a European multicentre survey. Arch Dis Child. 2009; 94(6): 429-433. DOI: 10.1136/adc.2008.151688. [Link]

10. Whittingham K. Parents of children with disabilities, mindfulness and acceptance: A review and a call for research. Mindfulness. 2014; 5(6): 704-709. https:// doi.org/10.1007/s12671-013-0224-8 [Link]

11.Kabat-Zinn J, Kabat-Zinn M. Everyday blessings: The inner work of mindful parenting. New York: Hyperion; 1997. [Link]

12.de Bruin E, Zijlstra BH, Geurtzen N, van Zundert RP, van de Weijer-Bergsma E, Hartman E, et al. Mindful parenting assessed further: Psychometric properties of the Dutch version of the Interpersonal Mindfulness in Parenting scale (IM-P). Mindfulness. 2014; 5(2): 200212. DOI: 10.1007/s12671-012-0168-4 [Link]

13.Esmaeili M, Basiri N, khayer Z. The effects of mindfulness-based cognitive therapy (MBCT) on psychological well-being of mothers of children with learning disabilities. J Learning Disabilities. 2016; 6(1): 26-3. [Persian]. [Link]

14.Burgdorf V, Szabó M, Abbott MJ. The effect of mindfulness interventions for parents on parenting stress and youth psychological outcomes: A systematic review and meta-analysis. Front Physiol. 2019; 10:1336. [Link]

15.Motahhry Z S, Ahmady KH, Soleymani A A, Behzadpoor S. Effectiveness of Mindfulness on decreasing marital stress in ADHD children's mothers. J Psychological Researches. 2014; 5 (17): 13-28. [Persian]. [Link]

16.Coatsworth JD, Duncan LG, Nix RL, Greenberg MT, Gayles JG, Bamberger KT, et al. Integrating mindfulness with parent training: Effects of the Mindfulness-Enhanced Strengthening Families Program. Dev Psychol. 2015; 51(1): 26-35. DOI: 10. 1037/a0038212 [link]

17.Duncan L, Coatsworth JD, Gayles JG, Geier MH, Greenberg MT. Can mindful parenting be observed? Relations between observational ratings of motheryouth interactions and mothers' self-report mindful parenting. J Fam Psychol. 2015; 29(2): 276-282. DOI: 10.1037/a0038857 [link]

18. Aghajani S, Afrooz G A, Narimani M, Ghobari Bonab B, Mohsenpour Z. The Effectiveness of MindfulnessBased Stress Reduction on Mother-Child Interaction among Mothers with Intellectually Disabled Children. Journal of Exceptional Children. 2015; 15 (1): 75-84. [Persian]. [Link]

19.Moradiyani Gizeh Rod S, Mir Drikvand F, Hosseini Ramaghani N, Mehrabi M. The Effectiveness of Mindfulness-based Parenting Training on Anxiety, Depression and Aggression of Mothers with Children Suffering from Oppositional Defiant Disorder. Armaghane danesh. 2016; 21(6): 576-590. [Persian]. [Link] 
20.Duncan L, Coatsworth JD, Greenberg M. A model of mindful parenting: Implications for parent-child relationships and prevention research. Clin Child Fam Psychol Rev. 2009; 12(3): 255-270. DOI: 10.1007/ s10567-009-0046-3 [Link]

21.Burke L, Adler-Baeder F, McGill J. Mindfulness, Parenting Efficacy and Child Age: Does the Facet of Mindfulness Matter? Southeastern Council on Family Relations Conference. 2018. [Link]

22. Sabatelli RM, Waldron RJ. Measurement issued in the assessment of the experiences of parenthood. J Marriage Fam. 1995; 57(4): 969-980. https://doi.org/ 10.2307/353416 [Link]

23. Arellano A, Denne LD, Hastings RP, Hughes JC. Parenting sense of competence in mothers of children with autism: Associations with parental expectations and levels of family support needs. J Intellect Dev Disabil. 2019; 44(2): 212-218. https://doi.org/ 10. 31 09/13668250.2017.1350838 [Link]

24.Raby KL, Lawler JM, Shlafer RJ, Hesemeyer PS, Collins WA, Sroufe LA. The interpersonal antecedents of supportive parenting: A prospective, longitudinal study from infancy to adulthood. Dev Psychol. 2015; 51(1):115-123. DOI: $10.1037 /$ a003 8336 [Link]

25.Bögels SM, Hellemans J, van Deursen S, Römer M, van der Meulen R. Mindful parenting in mental health care: effects on parental and child psychopathology, parental stress, parenting, coparenting, and marital functioning. Mindfulness. 2014; 5(5): 536-551. https: //doi.org/10.1007/s12671-013-0209-7 [Link]

26. Sedighi Arfaee F, Hesampour F. The relationship between mindfulness and perceived social support and mental health in mothers of children with intellectual disability. J Social Work. 2015; 4 (4): 42-52 [Persian]. [Link]

27. Gholami Jam F, Takaffoli M, Kamali M, Eslamian A, Alavi Z, Ali Nia V. Systematic Review on Social Support of Parent/Parents of Disabled Children. Archives of Rehabilitation. 2018; 19 (2):126-141. [Persian]. [Link]

28.Gecková A, Van Dijk JP, Stewart R, Groothoff JW, Post D. Influence of social support on health among gender and socio-economic groups of adolescents. Eur J Public Health. 2003; 13(1): 44-50. DOI: 10. 1093/ eurpub/13.1.44 [Link]

29. Cohen S, Underwood LG, Gottlieb BH, (Eds.) Social support measurement and intervention: A guide for health and social scientists. Oxford University Press; 2000. [Link]
30.Özyazıcıoğlu N, Buran G. Social support and anxiety levels of parents with disabled children. Rehabil Nurs. 2014; 39(5): 225-231. DOI: 10.1002/rnj.137 [Link]

31.Davison KK, Birch LL. Childhood overweight: a contextual model and recommendations for future research. Obes Rev. 2001; 2(3): 159-171. DOI: 10.1046/j.1467-789x.2001. 00036.x [Link]

32.Helgeson VS, Cohen S. Social support and adjustment to cancer: reconciling descriptive, correlational, and intervention research. Health Psychol. 1996; 15(2): 135-148. DOI: 10.1037//0278-6133.15.2.135 [Link]

33.Lunsky Y, Bramston P. A preliminary study of perceived stress in adults with intellectual disabilities according to self-report and informant ratings. J Intellect Dev Disabil. 2006; 31(1): 20-27. https:// doi.org/10.1080/13668250500488660 [Link]

34. Shakib N, Hashemi Razini H. Causal Relationship between Social Support and Parenting Stress with Parenting Styles of Mothers of Children with Intellectual Disabilites with the Mediating Role of Cognitive-Emotional Regulation Strategies. J Child Ment Health. 2017; 4 (3): 37-48. [Persian]. [Link]

35. Ghasemipour Y, RoshanBehnaaz B. Investigating the Relationship between Mindfulness and Social Support with Mental Health of Mothers with Mentally Retarded Child. J Child Ment Health. 2019; 6 (1):176187. [Persian]. [Link]

36. Mace C. Mindfulness and mental health: Therapy, theory and science. Routledge; 2007. [Link]

37.Duncan LG. Assessment of mindful parenting among parents of early adolescents: Development and validation of the Interpersonal Mindfulness in Parenting scale. Human Development and Family Studies at the Pennsylvania State University (Doctorate Thesis); 2007. [Link]

38. Mikaeili N, Mohajeri Aval N, Otared N. The Role of Mindful Parenting Style and Maternal Attachment Style in Predicting the Behavioral Disorders on ADHD Children. J Women \& Culture. 2017; 9(32): 21-36. [Persian]. [Link]

39.Gibaud-Wallston J, Wandersman LP. Development and utility of the Parenting Sense of Competence Scale. Paper presented at the annual meeting of the American Psychological Association, Toronto. 1978. [Link]

40.Johnston C, Mash EJ. A measure of parenting satisfaction and efficacy. J Clin Child Psychol. 1989; 18 (2): 167-175. https://doi.org/ 10.1207/ s15374424 jccp1802_8 [Link]

41.Rashid K, Hosseini Nazarlou M. Investigating the Effect of Sex Education on Enhancing Parents' Sexual 
Knowledge and their Sense of Competence. J Instruction and Evaluation. 2017; 10(37): 143-162. [Persian]. [Link]

42.Zimet GD, Dahlem NW, Zimet SG, Farley GK. The multidimensional scale of perceived social support. J Pers Assess. 1988; 52(1): 30-41. https://doi.org/ 10. 1207/ s15327752jpa5201_2 [Link]

43.Edwards LM. Measuring perceived social support in Mexican American youth: Psychometric properties of the multidimensional scale of perceived social support. Hisp J Behav Sci. 2004; 26(2): 187-194. https://doi.org/10.1177/0739986304264374 [Link]
44. Sheikholslamy A, Sadeghi Valni Z, Mohammadi N. The Relationship of Resiliency and Perceived Social Support with Adjustment of Mothers with Intellectually Disable Child. Psychology of Exceptional Individuals. 2015; 5(20): 125-139. [Persian]. [Link]

45.Meyers LS, Gamst G, Guarino AJ. Applied multivariate research: Design and interpretation. Thousand Oaks: Sage Publications; 2006, pp: 147195. [Link] 